\title{
Synthesis, Characterization and the Solvent Effects on Interfacial Phenomena of Jatropha Curcas Oil Based Non-Isocyanate Polyurethane
}

\author{
Mhd. Abd. Cader M. Haniffa ${ }^{1,2}$, Yern Chee Ching ${ }^{1, *}$, Cheng Hock Chuah ${ }^{2}$, Yong Ching Kuan ${ }^{3}$, \\ De-Shin Liu ${ }^{4}$ and Nai-Shang Liou ${ }^{5}$ \\ 1 Department of Chemical Engineering, Faculty of Engineering, University of Malaya, \\ 50603 Kuala Lumpur, Malaya; cader@siswa.um.edu.my \\ 2 Department of Chemistry, Faculty of Science, University of Malaya, 50603 Kuala Lumpur, Malaya; \\ chchuah@um.edu.my \\ 3 University of Reading Malaysia, Persiaran Graduan, Kota Ilmu, Educity, 79200 Iskandar Puteri, \\ Johor, Malaysia; K.Y.Ching@reading.edu.my \\ 4 Department of Mechanical Engineering, National Chung-Cheng University, Chia-Yi 62102, Taiwan; \\ liu@ccu.edu.tw \\ 5 Department of Mechanical Engineering, Southern Taiwan University of Science and Technology, \\ Tainan City 710, Taiwan; nliou@stust.edu.tw \\ * Correspondence: chingyc@um.edu.my; Tel.: +60-37-967-4445
}

Academic Editor: Philipp Vana

Received: 27 March 2017; Accepted: 25 April 2017; Published: 1 May 2017

\begin{abstract}
Non-isocyanate polyurethane (NIPU) was prepared from Jatropha curcas oil (JCO) and its alkyd resin via curing with different diamines. The isocyanate-free approach is a green chemistry route, wherein carbon dioxide conversion plays a major role in NIPU preparation. Catalytic carbon dioxide fixation can be achieved through carbonation of epoxidized derivatives of JCO. In this study, 1,3-diaminopropane (DM) and isophorone diamine (IPDA) were used as curing agents separately. Cyclic carbonate conversion was catalyzed by tetrabutylammonium bromide. After epoxy conversion, carbonated JCO (CJCO) and carbonated alkyd resin (CC-AR) with carbonate contents of 24.9 and $20.2 \mathrm{wt} \%$, respectively, were obtained. The molecular weight of CJCO and CC-AR were determined by gel permeation chromatography. JCO carbonates were cured with different amine contents. CJCO was blended with different weight ratios of CC-AR to improve its characteristics. The cured NIPU film was characterized by spectroscopic techniques, differential scanning calorimetry, and a universal testing machine. Field emission scanning electron microscopy was used to analyze the morphology of the NIPU film before and after solvent treatment. The solvent effects on the NIPU film interfacial surface were investigated with water, $30 \%$ ethanol, methyl ethyl ketone, $10 \% \mathrm{HCl}, 10 \% \mathrm{NaCl}$, and $5 \%$ $\mathrm{NaOH}$. NIPU based on CCJO and CC-AR (ratio of 1:3) with IPDA crosslink exhibits high glass transition temperature $\left(44^{\circ} \mathrm{C}\right)$, better solvent and chemical resistance, and Young's modulus (680 MPa) compared with the blend crosslinked with DM. Thus, this study showed that the presence of CC-AR in CJCO-based NIPU can improve the thermomechanical and chemical resistance performance of the NIPU film via a green technology approach.
\end{abstract}

Keywords: Jatropha curcas oil; non-isocyanate polyurethane; solvent resistant; chemical resistance; surface phenomena

\section{Introduction}

Raw materials, the petroleum rate, resource depletion, and the awareness of the consumer society have increased worldwide attention on environmental issues and the growing concern for 
polyurethane (PU) materials. These issues have facilitated research on biodegradable and renewable green resources $[1,2]$. Compared with other renewable raw materials, vegetable oils (VOs) have attracted significant attention because of their low toxicity and environmental, regenerative, economic, and social advantages in the application of PU materials [1,3-6]. Jatropha curcas oil (JCO) is one of the attractive vegetable oils for the oleochemical industry [7-11]. JCO has high unsaturated fatty acid content and good oxidation stability [8], which make it a suitable raw material for many non-isocyanate polyurethane industrial applications [12] such as adhesives [13,14], alkyd epoxy resins [15], food packaging [16], surface coatings [17], nanocomposites [18], etc. Table 1 shows the characteristics of JCO compared to other type of vegetable oils. The low temperature viscosity $\left(<25^{\circ} \mathrm{C}\right)$ and acidic property of JCO are lower than those of soybean, linseed, and castor oils $[19,20]$. These properties increased the production of JCO as a biodiesel component and lubricant [21]. Different synthetic routes to modify JCO have been investigated to achieve this target. Epoxidation and transesterification have received increasing attention in recent years [21,22]. By contrast, $\mathrm{CO}_{2}$ transformation is a sustainable solution for controlling global warming and serves as a reusable resource for $\mathrm{CO}_{2}$ valorization.

Table 1. Characteristics of jatropha curcas oil compared to other types of vegetable oils.

\begin{tabular}{ccccccccc}
\hline Oil & C 18:3 (\%) & C 18:2 (\%) & C 18:1 (\%) & RA & SFA & V/mPa s & $\mathbf{M}_{\mathbf{w}} / \mathbf{g} \cdot \mathbf{m o l}^{-\mathbf{1}}$ & $\mathbf{A V} / \mathbf{m g} \cdot \mathbf{K O H} \cdot \mathbf{g}^{-\mathbf{1}}$ \\
\hline SBO & $7-10$ & 51 & 23 & 0 & 14 & 54.3 & 879.4 & 2.7 \\
LSO & 56 & 17 & 24 & 0 & $10.4-11.6$ & 48.4 & $887.4[23]$ & 4.0 \\
JCO & 0 & 45.15 & 39.5 & 0 & 14.3 & 42.3 & 900.0 & 2.6 \\
CSO & 0.75 & 3 & 44 & 90 & 1.5 & 700 & $927.0[24]$ & 2.0 \\
\hline
\end{tabular}

$\mathrm{SBO}=$ soybean oil, $\mathrm{LSO}=$ linseed oil, $\mathrm{CSO}=$ castor oil, $\mathrm{SFA}=$ saturated fatty acid, $M_{\mathrm{w}}=$ molecular weight, $\mathrm{AV}=$ acid value, $\mathrm{RA}=$ ricinoleic acid, $\mathrm{V}=$ viscosity.

The chemical fixation of $\mathrm{CO}_{2}$ into oxiranes, which produce five-member cyclic carbonates, has attracted economic and environmental attention. $\mathrm{CO}_{2}$ fixation into oxiranes is typically performed under various pressures and temperatures in the presence of the tetrabutylammonium bromide (TBAB) catalyst. TBAB is one of the most widely used homogenous catalysts that can decompose toxic and volatile compounds, such as hydrogen bromide, which is highly reactive with epoxy groups, at a high temperature [25]. However, other catalysts, such as silica-supported 4-pyrrolidinopyridium iodide, $\mathrm{Pt}$-doped $\mathrm{H}_{3} \mathrm{PW}_{12} \mathrm{O}_{40} / \mathrm{ZrO}_{2}$, and $\mathrm{KI}$ with 18-crown- 6 ether, have been tested. These catalysts exhibited low efficiency. The performance of TBAB has been enhanced by co-catalysts, such as $\mathrm{CaCl}_{2}$ and $\mathrm{SnCl}_{4} \cdot 5 \mathrm{H}_{2} \mathrm{O}$ [26]. TBAB is used as a co-catalyst in the $\mathrm{AlCl}$ catalyst system for the $\mathrm{CO}_{2}$ fixation process [27]. The decomposition temperature of TBAB is a key factor in catalytic carbon dioxide fixation, and Zheng et al. determined that the decomposition temperature of TBAB is $130{ }^{\circ} \mathrm{C}$ [26].

The nature of the reactor system and its reaction time are interdependent. Tamami et al. [28] were the first to apply the flow of $\mathrm{CO}_{2}$ to synthesize carbonated soybean oil under atmospheric pressure at $110^{\circ} \mathrm{C}$ using $5 \%$ of TBAB as a catalyst. They observed viscosity enhancement and a slow reaction rate during this reaction [29,30]. Mazo and Rios [30] reported improved carbonation kinetics. Doll and Erhan [25] intensified the carbonation process to achieve a high yield in a short time under supercritical $\mathrm{CO}_{2}$ and achieved $94 \%$ conversion in $20 \mathrm{~h}$. The aminolysis of a five-member ring cyclic carbonate oligomer was intensified by the catalyst to produce efficient PU or PU-like materials under mild conditions [31]. This alternative pathway produces an isocyanate-free PU network and makes it stronger via $\beta$-hydroxyurethane linkages with promising chemistries [32].

Compared with conventional PU, ocyanate-free PU materials (i.e., non-isocyanate polyurethane (NIPU)) have lower permeability, better hydrolytic stability properties, and a safer fabrication process.

The formation of intramolecular hydrogen bonds via the hydroxyl group at the $\beta$-carbon atom in the PU chain enhances chemical resistance two times higher than the conventional PU [32]. NIPUs are insensitive to moisture in fillers or surfaces because of this unique molecular behavior. Surface interfacial phenomena are extremely versatile [33-36] and are a precise way to analyze the supramolecular chemistry of the material surface [37]. The surface properties depend on the surface 
charge developed by the functional moieties of the material, which are specific to the different segments of the NIPU network [33]. These segments establish different sorption processes with polarized molecular species in different solvent environments [38].

The major objective of this study is to optimize the reaction parameters, such as temperature and carbonation pressure, of epoxidized JCO, to assess the thermomechanical properties and the chemical resistance properties of cured JCO films and their blends based on NIPU. To the best of our knowledge, industrial JCO has not been previously investigated in NIPU production. Optimizing the cost-effective reaction parameters of CCJO is essential at the scale-up stage to facilitate mass production of JCO-based PU materials at the industrial level. Figure 1 illustrates the catalytic carbon dioxide fixation via carbonation of epoxidized JCO (CJCO). Figure 2 shows the reaction scheme of the cyclic carbonation of epoxidized alkyd resin (CC-AR). The isocyanate-free polymerization network was applied at different weight ratios of CCJO and CC-AR with 1,3-diaminopropane (DM) and isophorone diamine (IPDA). Thermomechanical, solvent, and chemical resistance properties were also investigated.

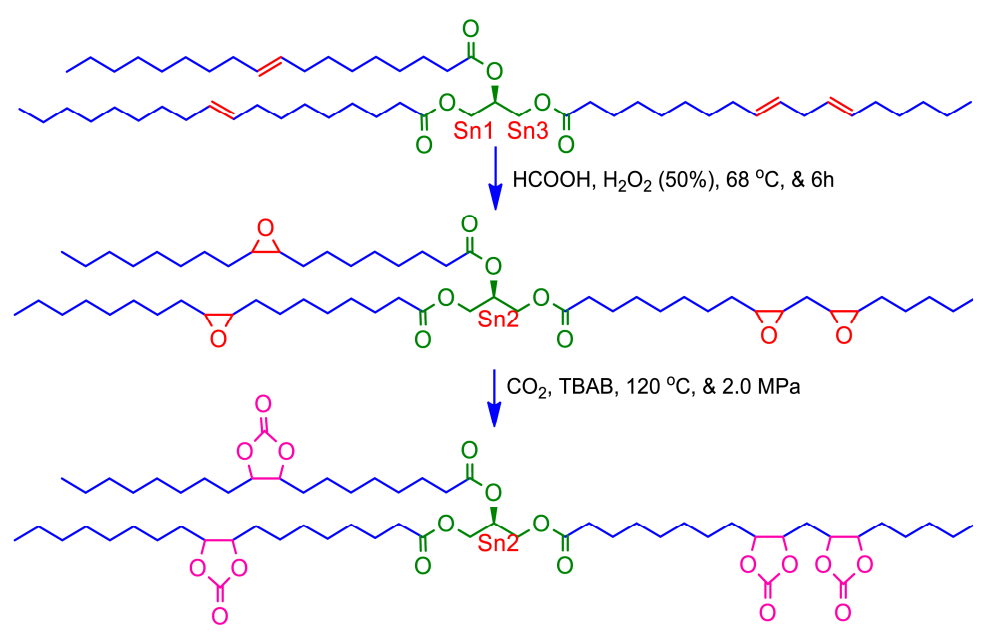

Figure 1. Schematic representation of catalytic carbon dioxide fixation via carbonation of epoxidized JCO (CJCO).

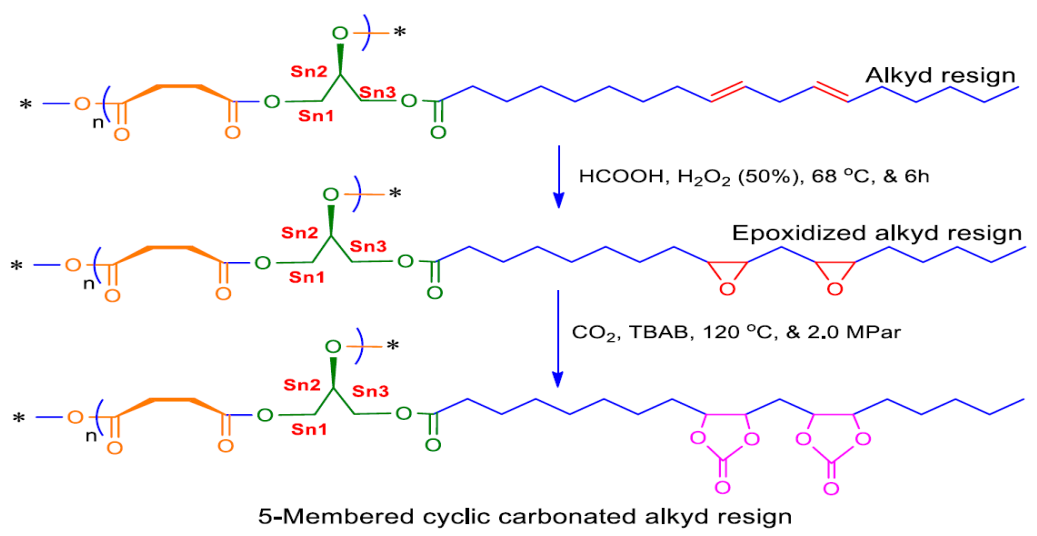

Figure 2. Reaction scheme of cyclic carbonation of epoxidized alkyd resin (CC-AR).

\section{Materials and Methods}

\subsection{Materials}

JCO was supplied by the Wahum Edible Oil Sdn. Bhd. (Cyberjaya, Malaysia). DM, ethyl acetate, acetic anhydrate, benzene, formic acid $(\mathrm{HCOOH} ; 85 \%)$, hydrogen peroxide $\left(\mathrm{H}_{2} \mathrm{O}_{2} ; 50 \%\right)$, 
$\mathrm{H}_{2} \mathrm{SO}_{4}$, pyridine, $\mathrm{CaO}, \mathrm{HCl}, \mathrm{NaCl}, \mathrm{NaOH}, \mathrm{TBAB}, \mathrm{IPDA}, \mathrm{CO}_{2}$, methyl ethyl ketone (MEK), perchloric acid, denatured ethanol, $\mathrm{KOH}$, phenolphthalein, sodium bicarbonate, anhydrous sodium sulfate, triethylamine, and tetrahydrofuran were purchased from Sigma-Aldrich (Kuala Lumpur, Malaysia). All materials were used as received without any further purification.

\subsection{Synthesis and Characterization of JCO Based Cyclic Carbonates}

CJCO is obtained through a two-step synthesis, as shown in Figure 1. The first step involves the epoxidation of JCO with $\mathrm{H}_{2} \mathrm{O}_{2}$ in the presence of formic acid. The second step involves catalytic carbon dioxide fixation through carbonation of the epoxidized JCO (EJCO).

\subsubsection{Preparation of EJCO}

JCO epoxidation was conducted in a three-necked round-bottom flask that contains formic acid $(4.6 \mathrm{~g})$ with JCO $(100 \mathrm{~g})$. Hydrogen peroxide $(115.6 \mathrm{~g}, 50 \%(w / v))$ was added to the flask with continuous stirring. The reaction mixture was maintained at $65^{\circ} \mathrm{C}$ for $6 \mathrm{~h}$. The resulting mixture was washed with distilled water, followed by sodium bicarbonate solution until it reached a neutral $\mathrm{pH}$. The oily phase was collected and dried with anhydrous sodium sulfate.

An ultrasonication-assisted titration method was used to determine the epoxy value (Equation (1)). The epoxy conversion was then calculated using Equation (2).

$$
\begin{gathered}
\text { Epoxy value }(\mathrm{EV})=\frac{\left(V_{0}-V\right) \times N}{W \times 10} \\
\text { Epoxy conversion }(E C)=\frac{E V}{W} \times 100 \%
\end{gathered}
$$

where $V_{0}$ is a required volume of the $\mathrm{NaOH}$ solution $(\mathrm{mL})$ for blank titration; $V$ is a required volume of the $\mathrm{NaOH}$ solution $(\mathrm{mL})$ to titrate the hydrochloric acid-acetone solution with dissolved sample; $N=$ normality of $\mathrm{NaOH}$ standard aqueous solution and $\mathrm{W}$ is the mass $(\mathrm{g})$ of the sample used for the titration.

\subsubsection{Preparation of $\mathrm{CJCO}$}

Catalytic carbon dioxide fixation via the carbonation of EJCO was conducted in the presence of TBAB using a $\mathrm{CO}_{2}$ pressure reactor. EJCO $(100 \mathrm{~g})$ was transferred into the reactor. Then, carbon dioxide and TBAB $(3.5 \mathrm{~g})$ were added and heated to $120^{\circ} \mathrm{C}$. Complete conversion was monitored by Fourier transformed infrared (FTIR) spectroscopy, proton nuclear magnetic resonance $\left({ }^{1} \mathrm{H}-\mathrm{NMR}\right)$ spectroscopy, and titration measurements. Epoxy conversion was measured at different temperatures and pressures that range from 110 to $140^{\circ} \mathrm{C}$ and from 1.0 to $2.0 \mathrm{MPa}$, respectively.

The carbonated content of the purified sample was determined from characteristic peaks of cyclic carbonate using the equations given below as described previously by Cornille et al. [39]. A standard solution of DMSO with toluene (60 mg of toluene in $10 \mathrm{~mL}$ of DMSO- $d_{6}$ ) and a specific amount of cyclic carbonate (around $30 \mathrm{mg}$ ) were weighted and then put into an NMR tube for carbonate content determination.

$$
\begin{gathered}
\mathrm{CEW}=\frac{m \times I_{\mathrm{CH}_{3}}}{I_{\mathrm{CC}} \times n_{\text {toluene }}} \\
\text { Carbonate content }=\frac{\mathrm{CEW}}{m} \times \mathrm{EC} \times 100 \%
\end{gathered}
$$

where $I_{\mathrm{CC}}$ is the total integral area of the characteristic peaks of cyclic carbonate; and $I_{\mathrm{CH}_{3}}$ is the integral area of the characteristic peak of the $-\mathrm{CH}_{3}$ group of the toluene in the ${ }^{1} \mathrm{H}$-NMR spectra; $n_{\text {toluene }}$ is the molar amount of toluene introduced in the standard solution; $\mathrm{CEW}$ is a carbonate equivalent weight and $\mathrm{m}$ is the mass of the sample introduced in the ${ }^{1} \mathrm{H}-\mathrm{NMR}$ tube. 


\subsubsection{Optimization of the Reaction Parameters of CJCO}

The conversion yield of EJCO to CJCO was determined within the temperature range of $100^{\circ} \mathrm{C}$ to $140{ }^{\circ} \mathrm{C}$ and pressure range of 1.0 to $2.0 \mathrm{MPa}$ with a constant amount of TBAB. The yield of the catalytic carbon dioxide fixation via carbonation of EJCO was monitored by FTIR and ${ }^{1} \mathrm{H}-\mathrm{NMR}$ spectroscopy. The carbonation yield increased with the increase in temperature with the Arrhenius law. Moreover, the mass transfer kinetics increased with the increase in reaction temperature [40].

In the present study, high reaction temperatures of 130 to $140{ }^{\circ} \mathrm{C}$ exhibited low conversion yield of five-member cyclic carbonate. However, a high yield was achieved at $120^{\circ} \mathrm{C}$ under $2.0 \mathrm{MPa}$, as shown in Figure 3a. This finding could be attributed to the thermal decomposition and mass loss of TBAB, which significantly influences the catalytic carbon dioxide fixation [41]. Figure $3 \mathrm{~b}$ shows no significant differences in the initial carbonation yield between 1.0 and $2.0 \mathrm{MPa}$ of $\mathrm{CO}_{2}$. However, the carbonation yield of EJCO varied after $30 \mathrm{~h}$. Furthermore, Motokura et al. [42] have observed certain advantages in increasing the $\mathrm{CO}_{2}$ pressure between 3.0 and $5.0 \mathrm{MPa}$ at $130^{\circ} \mathrm{C}$ within a $7 \mathrm{~h}$ reaction period. In this study, the high carbonation period of $30 \mathrm{~h}$ and the stability of TBAB at low temperature were linked to a high $\mathrm{CO}_{2}$ gradient. Figure 5 shows the high carbonation yield at a low reaction pressure of $2.0 \mathrm{MPa}$ and low temperature of $120^{\circ} \mathrm{C}$. Considering the thermal stability of TBAB and the carbonation yield with respect to the $\mathrm{CO}_{2}$ pressure, it could be stated that the optimal carbonation conditions would occur at the temperature of $120^{\circ} \mathrm{C}$ and under the pressure of $2.0 \mathrm{MPa}$ of $\mathrm{CO}_{2}$ with a fixed amount of $3.5 \mathrm{~mol} \%$ of TBAB. Table 2 shows the comparative reaction parameters used for cyclic carbonation of various VOs in the presence of TBAB.

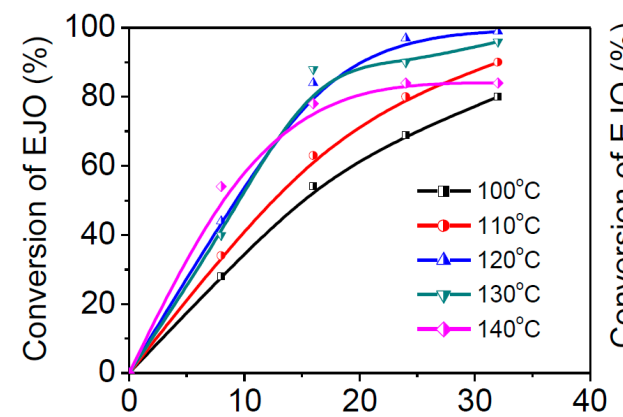

(a) Time /h

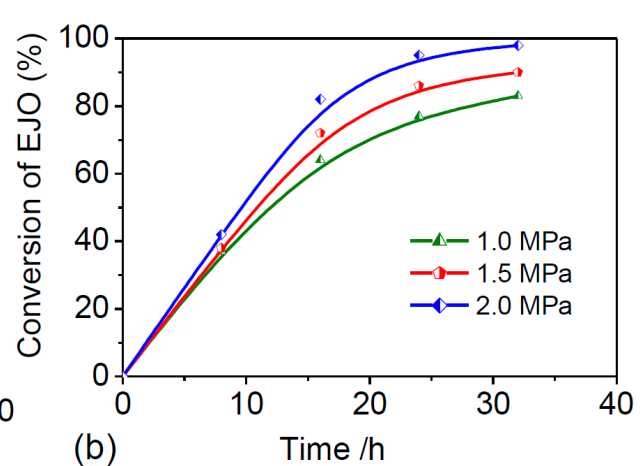

Figure 3. The effect of reaction parameters on the carbonation yield of EJCO at a fixed amount of $3.5 \mathrm{~g}$ of TBAB (a) Influence of temperature at 2.0 MPa and (b) Influence of pressure at $120^{\circ} \mathrm{C}$.

Table 2. The comparison reaction parameters used for cyclic carbonation of various VOs in the presence of TBAB.

\begin{tabular}{ccccccc}
\hline Oil & $\begin{array}{c}\text { Nature of the } \\
\text { Reactor System }\end{array}$ & $\mathbf{T} /\left({ }^{\circ} \mathbf{C}\right)$ & $\boldsymbol{P} /(\mathbf{M P a})$ & $\boldsymbol{R T} / \mathbf{( h )}$ & $\boldsymbol{C} /(\mathbf{\%})$ & Reference \\
\hline JCO & Pressure reactor & 120 & 2.0 & 30 & 99 & Present study \\
ESBO & Flow of $\mathrm{CO}_{2}$ & 110 & 0.101 & 70 & 94 & Tamami et al. [27] \\
ESBO & MI with flow of $\mathrm{CO}_{2}$ & 120 & 0.101 & 40 & 95 & Mazo and Rios [29] \\
ECSO & Autoclave & 140 & 3.000 & 24 & 100 & Zhang et al. [4] \\
ESBO & Autoclave/sc $\mathrm{CO}_{2}$ & 100 & 10.300 & 20 & 94 & Doll and Erhan [22] \\
ESBO & Pressure reactor & 140 & 5.650 & 20 & 100 & Javni et al. [28] \\
ELO & Pressure reactor & 140 & 3.000 & 20 & 100 & Bähr and Mülhaupt [43] \\
\hline
\end{tabular}

$T=$ temperature, $P=\mathrm{CO}_{2}$ pressure, $R T=$ reaction time, $\mathrm{C}=$ conversion, $\mathrm{MI}=$ microwave irradiation, $\mathrm{ESBO}=$ epoxidized soybean oil, ECBO = epoxidized cottonseed oil, $\mathrm{ELO}=$ epoxidized linseed oil. 


\subsection{Synthesis of JCO-Based Catalytic Carbonated Alkyd Resin}

\subsubsection{Preparations of JCO-Based Monoglyceride Alkyd Resin}

A mixture of glycerol and JCO was placed in a three-necked round-bottom flask connected to a reflux tube, a $\mathrm{N}_{2}$ gas inlet, and a thermometer. The flask was immersed in the oil bath placed in a magnetic stirrer. The reaction was maintained at $230{ }^{\circ} \mathrm{C}$ for $1.5 \mathrm{~h}$ in the presence of $0.03 \mathrm{wt} \% \mathrm{CaO}$ and was continued until a drop of reaction mixture could be completely dissolved by the methanol. (The drop of reaction mixture was cooled down first to $40^{\circ} \mathrm{C}$ at normal atmosphere before adding into methanol). The reaction mixture was then cooled to $120^{\circ} \mathrm{C}$ and $0.12 \mathrm{~mol}$ of succinic anhydride was added to the mixture. The temperature of the mixture was increased to $240{ }^{\circ} \mathrm{C}$ and was maintained until an acid value in the range of 10-15 was obtained. The synthezised alkyd resin was used for the preparation of EAR and CC-AR in the following steps.

\subsubsection{Preparation of Epoxidation and Cyclic Carbonation of JCO-Based Alkyd Resin (CC-AR)}

The epoxidation and cyclic carbonation of alkyd resin were conducted by following the same procedures as that of the functional group modification of JCO, as shown in Figure 2. The synthesis method of CC-AR was similar to the synthesis of CJCO. Since the optimization has been done on the CJCO synthesis, the same optimization parameters were also used for the preparation of CC-AR.

\subsection{Synthesis and Characterization of CJCO and Its Blends Based on NIPU}

JCO-based non-isocyanate polyurethane (NIPU) was prepared using the different compositions of CJCO and CC-AR in the presence of trimethylamine. The calculated amounts of CJCO, CC-AR, and diamine were transferred into a three-necked round-bottom flask that contained MEK. The feed weight of amine was determined based on the mole ratio of amine to carbonate. The reaction mixture was heated to $70{ }^{\circ} \mathrm{C}$ for $8 \mathrm{~h}$ and to $100{ }^{\circ} \mathrm{C}$ for $10 \mathrm{~h}$ with continuous stirring at $600 \mathrm{rpm}$ to make NIPU with IPDA, as described previously [44]. Meanwhile, NIPU with DM was confirmed at $1 \mathrm{~h}$ by FTIR spectroscopy. FTIR spectroscopy was used to monitor the progress of the reaction. Then, the resulting mixture was placed into a $55^{\circ} \mathrm{C}$ oven overnight to remove moisture and trapped air. After the removal of excess water and trapped air, the mixture was poured onto a Teflon sheet using an applicator. The curing procedure was conducted at $70^{\circ} \mathrm{C}$ for $10 \mathrm{~h}$, followed by $120{ }^{\circ} \mathrm{C}$ for $4 \mathrm{~h}$.

\subsection{Characterization Study}

\subsubsection{Molecular Weight}

The molecular weight distribution of the samples was obtained by gel permeation chromatography (GPC-THF system) at $40{ }^{\circ} \mathrm{C}$ in the 510 pump with a flow rate of $1 \mathrm{~mL} \cdot \mathrm{min}^{-1}$.

\subsubsection{Structural Characterization}

FTIR spectroscopy was conducted to analyze the functional groups of the samples and cured NIPU film using the PerkinElmer Spectrum 400 FTIR spectrometer unit (PerkinElmer, Waltham, MA, USA)using the $\mathrm{KBr}$ pellet technique with the resolution of $4 \mathrm{~cm}^{-1}$ and 32 scans per recording. ${ }^{1} \mathrm{H}-\mathrm{NMR}$ spectroscopy was performed on a Bruker ARX 300 spectrometer (Bruker Biospin, Switzerland) operating at $600 \mathrm{~Hz}$ to study the chemical shifts of the protons and carbonate content using $\mathrm{CDCl}_{3}$ as a solvent, and chemical shifts $(\delta)$ were reported in parts per million. The surface morphology of the NIPU film was investigated using a field emission scanning electron microscope (FESEM, ZEISS Sigma 500, Jena, Germany) before and after solvent and chemical treatments.

\subsubsection{Thermo-Mechanical Properties}

Differential scanning calorimetry (DSC) was used to determine the glass transition temperature $T_{\mathrm{g}}$, wherein $10 \mathrm{mg}$ samples were heated on the TA DSC Q200 calorimeter (TA instrument, New Castle, 
DE, USA) from 10 to $250{ }^{\circ} \mathrm{C}$ at a heating rate of $10^{\circ} \mathrm{C} \cdot \mathrm{min}^{-1}$. The ultimate tensile strength, Young's modulus $(E)$, and percent elongation at break $\left(\varepsilon_{\max }\right)$ of the blends were obtained by a universal testing machine (Shimadzu AGS-X series, Tokyo, Japan) at room temperature. Five test specimens were used to obtain the mean value of all tests. The effect of carbonated alkyd resin on the thermomechanical properties of CJCO and its blends based on NIPU was investigated with respect to the mixing ratio of CJCO and CC-AR and the amine content.

\subsubsection{Solvent and Chemical Resistance Tests}

Solvent and chemical resistance tests were conducted in different solvent environments. Water, ethanol (30\% aq.), $\mathrm{MEK}, \mathrm{NaOH}, \mathrm{HCl}$, and $\mathrm{NaCl}$ were used for this purpose.

\subsection{Characterization of EJCO and CJCO}

JCO was received as golden yellow oil, and the functional moieties of JCO were investigated by FTIR spectroscopy, as illustrated in Figure 4. The respective peaks were observed at $2926 \mathrm{~cm}^{-1}(-\mathrm{C}-\mathrm{H}$ symmetric stretching vibration of $-\mathrm{CH}_{2}$ groups), $2854 \mathrm{~cm}^{-1}$ (-C-H asymmetric stretching vibration of $-\mathrm{CH}_{2}$ groups), $1745 \mathrm{~cm}^{-1}$ ( $\mathrm{C}=\mathrm{O}$ stretching vibration), $1652 \mathrm{~cm}^{-1}$ (assigned to the $\left.-\mathrm{CH}=\mathrm{CH}-\right), 1464 \mathrm{~cm}^{-1}$ (- $\mathrm{CH}_{2}$ scissoring), $1243 \mathrm{~cm}^{-1}$ (- $\mathrm{CH}_{2}$ wagging), $1167 \mathrm{~cm}^{-1}$ (-C-O stretching of ester), and the peak at $760 \mathrm{~cm}^{-1}$ is attributed to $-\mathrm{CH}_{2}$ rocking vibration. The chemical shift of the JCO protons was examined by ${ }^{1} \mathrm{H}-\mathrm{NMR}$ as shown in Figure $5 \mathrm{~b}$, with the peaks between 5.5 and $5.32(\mathrm{a},-\mathrm{C} \underline{\mathrm{H}}=\mathrm{C} \underline{\mathrm{H}}-, 8 \mathrm{H}), 5.32-5.25$ (b, $\mathrm{C}-\underline{\mathrm{H}}-\mathrm{O}-\mathrm{C}=\mathrm{O}, 1 \mathrm{H}$, attributed to the sn-2 glycerol proton), 4.34-4.13 (d and $\mathbf{e}, \mathrm{C}_{2}-\mathrm{O}-\mathrm{C}=\mathrm{O}, 4 \mathrm{H}$, sn-1,3 glycerol protons), 2.85-2.75 (g, $\mathrm{CH}=\mathrm{CH}-\mathrm{CH}_{2}-\mathrm{CH}=\mathrm{CH}, 2 \mathrm{H}$, bisallylic group of $\left.\mathrm{C} 18: 2\right), 2.4-2.3$ $\left(\mathbf{h},-\mathrm{CH}_{2}-\mathrm{C}=\mathrm{O}, 6 \mathrm{H}\right), 2.1-2.0\left(\mathbf{I},-\mathrm{CH}_{2}-\mathrm{CH}=\mathrm{CH}-, 12 \mathrm{H}\right.$, allylic $-\mathrm{CH}_{2}$ group of $\mathrm{C} 18: 2$ and $\left.\mathrm{C} 18: 1\right), 1.69-1.58$ $\left(\mathbf{j}, \beta-\mathrm{CH}_{2}-, 6 \mathrm{H}\right), 1.41-1.24\left(\mathbf{k},-\underline{\mathrm{C}}_{2}\right.$-of fatty acid), and $0.93-0.88$ (1, terminal $\mathrm{CH}_{3}$ of fatty acid, $9 \mathrm{H}, \mathrm{sn}-1$, sn-2, sn-3 are stereospecific acyl carbons [45]).

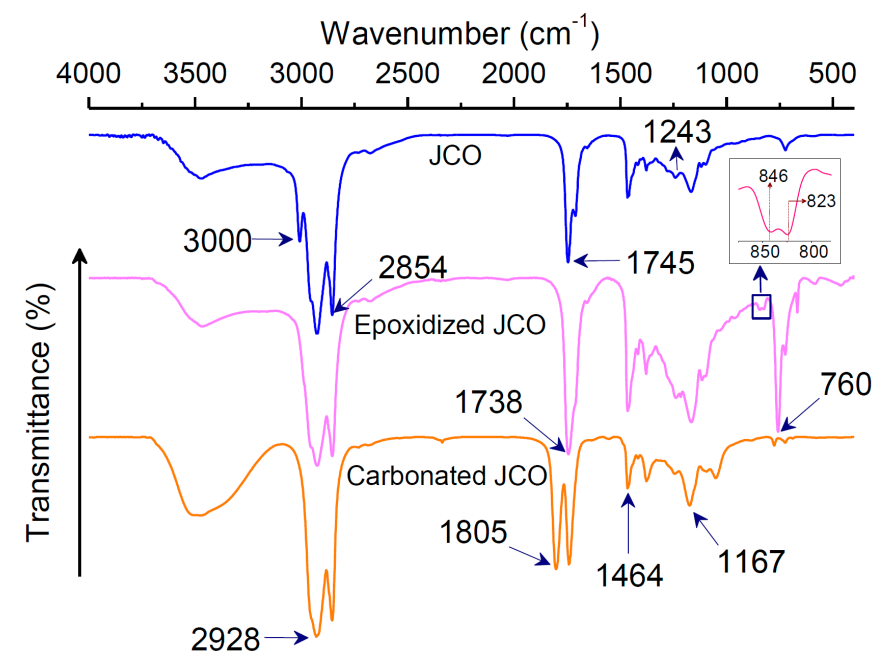

Figure 4. FTIR spectra of Jatropha curcas oil (JCO), epoxidized JCO, and carbonated JCO.

EJCO was obtained as a clear pale yellow viscous product. FTIR spectroscopy confirmed the epoxy ring formation with peaks at 846 and $823 \mathrm{~cm}^{-1}$, as shown in Figures 4 and $5 \mathrm{a} .{ }^{1} \mathrm{H}-\mathrm{NMR}$ spectroscopy exhibited the chemical shift of the EJCO protons, as illustrated in Figure $5 b$, with peaks between 5.30 and $5.25(\mathbf{a}, \mathrm{CH}-\mathrm{O}-\mathrm{C}=\mathrm{O}, 1 \mathrm{H}$, attributed to $s n-2$ glycerol proton) and between 4.36 and 4.12 (d and e, $\mathrm{CH}_{2}-\mathrm{O}-\mathrm{C}=\mathrm{O}, 4 \mathrm{H}, s n-1,3$ glycerol protons), 3.16-3.08 (f, $-\mathrm{CHOC} \underline{\mathrm{H}}-\mathrm{CH}_{2}-\mathrm{C}$ diepoxides of linoleic acid), 3.02-2.96 (f, $-\mathrm{CHOCH}-\mathrm{CH}_{2}-\mathrm{CHOC} \underline{\mathrm{H}}-$, diepoxides of linoleic acid), 2.96-2.89 (f, $-\mathrm{CH}_{2}-\mathrm{C} \underline{\mathrm{HOC}} \underline{\mathrm{H}}-\mathrm{CH}_{2}-$, epoxides of linoleic acid and its overlap with the epoxy oleic acid), 
2.4-2.3 (h, $\left.-\mathrm{CH}_{2}-\mathrm{C}=\mathrm{O}, 6 \mathrm{H}\right), 1.69-1.58\left(\mathbf{j}, \beta-\mathrm{CH}_{2}-, 6 \mathrm{H}\right), 1.41-1.24\left(\mathbf{k},-\underline{\mathrm{C}}_{2}-\right.$ of fatty acid), and 0.93-0.88 (1, terminal $\mathrm{CH}_{3}$ of fatty acid, $9 \mathrm{H}, s n-1, s n-2, s n-3$ are stereospecific acyl carbons [23]).

The carbonate content of triglyceride (JCO) and alkyd resin was calculated using the initial and final epoxy contents after the complete removal of TBAB. Ethyl acetate was used to separate TBAB from carbonated JCO. CJCO was obtained as a clear wine red viscous product. The peak at $1805 \mathrm{~cm}^{-1}$ of the FTIR spectra confirmed the formation of the five-member cyclic carbonate, as illustrated in Figure 4 . The chemical shift of the CJCO protons was examined by ${ }^{1} \mathrm{H}-\mathrm{NMR}$ spectroscopy, as shown in Figure $5 \mathrm{~b}$. The corresponding peaks were observed between 5.30 and $5.25(\mathrm{a}, \mathrm{C} \underline{\mathrm{H}}-\mathrm{O}-\mathrm{C}=\mathrm{O}, 1 \mathrm{H}$, sn-2 glycerol proton), 5.06-4.52 (c, - $\mathrm{CHOCOOC} \underline{\mathrm{H}}-\mathrm{CH}_{2}-\mathrm{C} \underline{\mathrm{HOCOOCH}}-$, carbonation of linoleic acid), 4.36-4.12 (d and e, $\underline{\mathrm{C}}_{2}-\mathrm{O}-\mathrm{C}=\mathrm{O}, 4 \mathrm{H}, s n-1,3$ glycerol protons), 2.96-2.89 (h, $-\mathrm{CH}_{2}-\mathrm{CHOC}_{\mathbf{H}}-\mathrm{CH}_{2}-$, the partial epoxides of linoleic acid and its overlap with the epoxy oleic acid), 2.4-2.3 (i, $-\mathrm{CH}_{2}-\mathrm{C}=\mathrm{O}$, $6 \mathrm{H}), 1.69-1.58\left(\mathrm{j}, \beta-\mathrm{CH}_{2}-, 6 \mathrm{H}\right), 1.41-1.24\left(\mathrm{k},-\mathrm{C}_{2}-\right.$ of fatty acid), and 0.93-0.88 (l, attributed to the terminal $\underline{\mathrm{C}}_{3}$ of the fatty acid, $\left.9 \mathrm{H}\right)$.

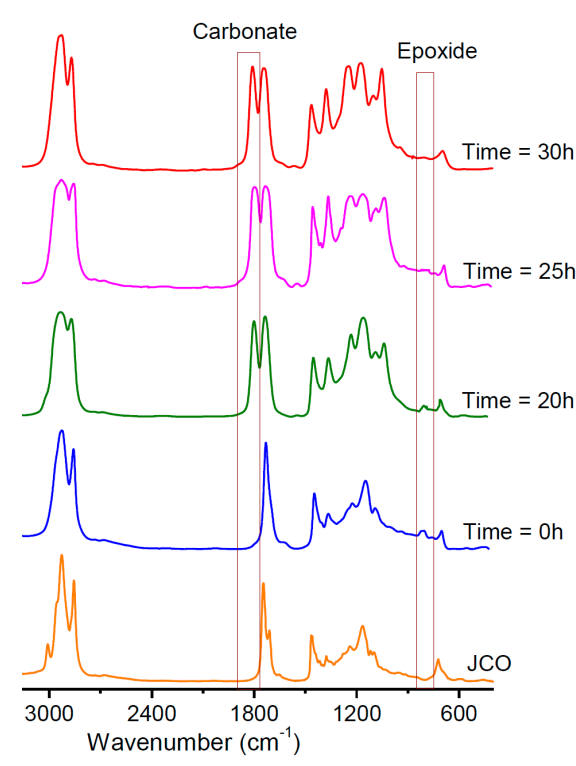

(a)

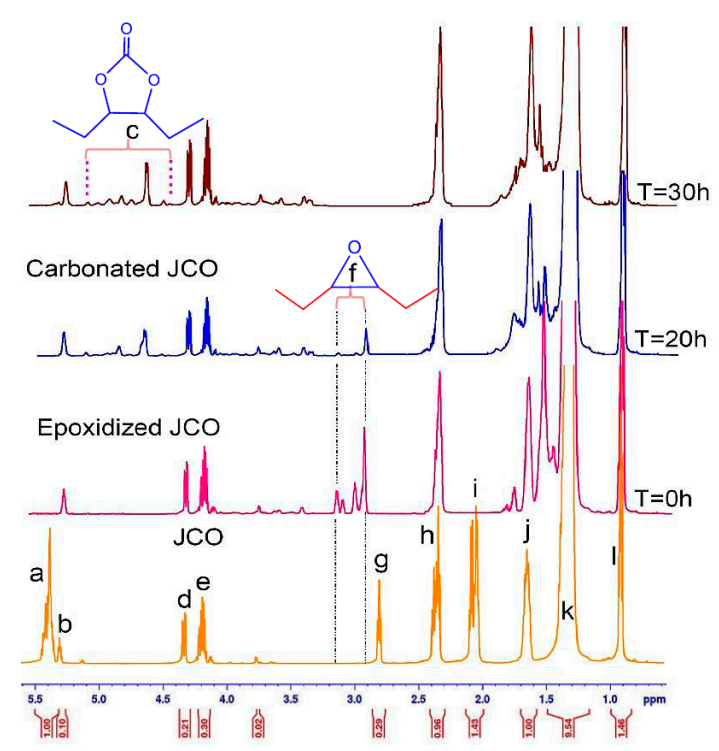

(b)

Figure 5. The spectra of (a) FTIR: (b) ${ }^{1} \mathrm{H}-\mathrm{NMR}$ at different reaction times at $120{ }^{\circ} \mathrm{C}, 2.0 \mathrm{MPa}$, and $3.5 \mathrm{~mol} \%$ of TBAB.

\section{Results and Discussion}

\subsection{Characterization of Monoglyceride, Alkyd Resin (AR), Epoxidized (EAR), and CC-AR}

FTIR and ${ }^{1} \mathrm{H}-\mathrm{NMR}$ analyses were applied to examine the corresponding peak confirmation and chemical shift of the monoglyceride, AR, EAR, and CC-AR protons. Scheme 1 illustrates the reaction scheme of the monoglyceride and AR synthesis. The FTIR spectrum of monoglyceride assigns the peaks at $3391 \mathrm{~cm}^{-1}$ (attributed to the hydroxyl groups of the monoglyceride of JCO) and $2855 \mathrm{~cm}^{-1}$ (-C-H asymmetric stretching vibration of $-\mathrm{CH}_{2}$ groups), $3464 \mathrm{~cm}^{-1}$ (attributed to the hydroxyl groups of the alkyd resin of JCO), $1740 \mathrm{~cm}^{-1}$ ( $\mathrm{C}=\mathrm{O}$ stretching vibration of monoglyceride), $1738 \mathrm{~cm}^{-1}$ ( $\mathrm{C}=\mathrm{O}$ stretching vibration of alkyd resin), $1652 \mathrm{~cm}^{-1}$ (assigned to the $-\mathrm{CH}=\mathrm{CH}-$ ), $1464 \mathrm{~cm}^{-1}$ (- $\mathrm{CH}_{2}$ scissoring), and $1243 \mathrm{~cm}^{-1}\left(-\mathrm{CH}_{2}\right.$ wagging), as illustrated in Figure $6 \mathrm{a}$. 


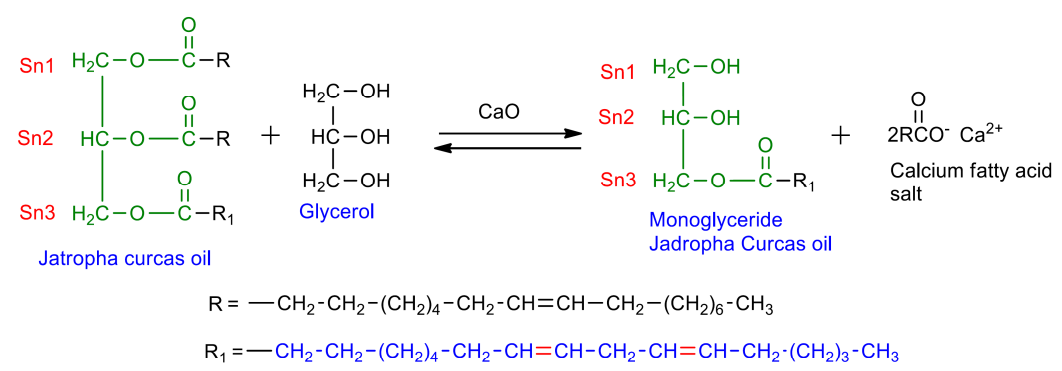

$\mathrm{R}_{1}=-\mathrm{CH}_{2}-\mathrm{CH}_{2}-\left(\mathrm{CH}_{2}\right)_{4}-\mathrm{CH}_{2}-\mathrm{CH}=\mathrm{CH}-\mathrm{CH}_{2}-\mathrm{CH}=\mathrm{CH}-\mathrm{CH}_{2}-\left(\mathrm{CH}_{2}\right)_{3}-\mathrm{CH}_{3}$

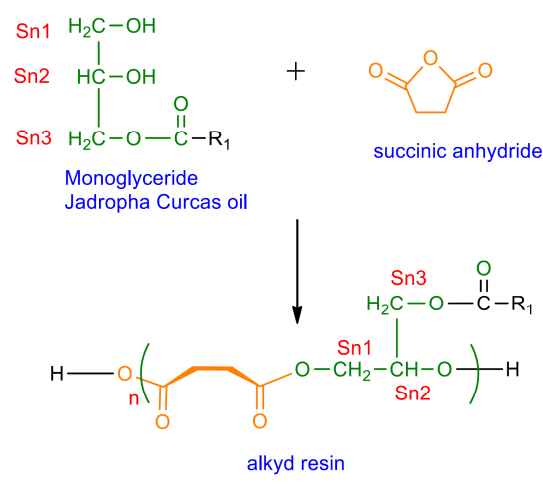

Scheme 1. Reaction scheme of monoglyceride and alkyd resin of the Jatropha curcas oil.

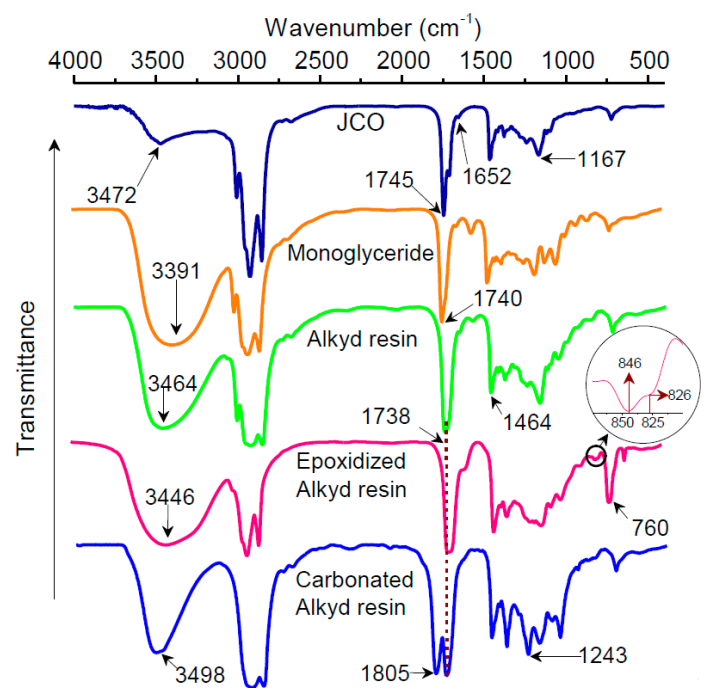

(a)

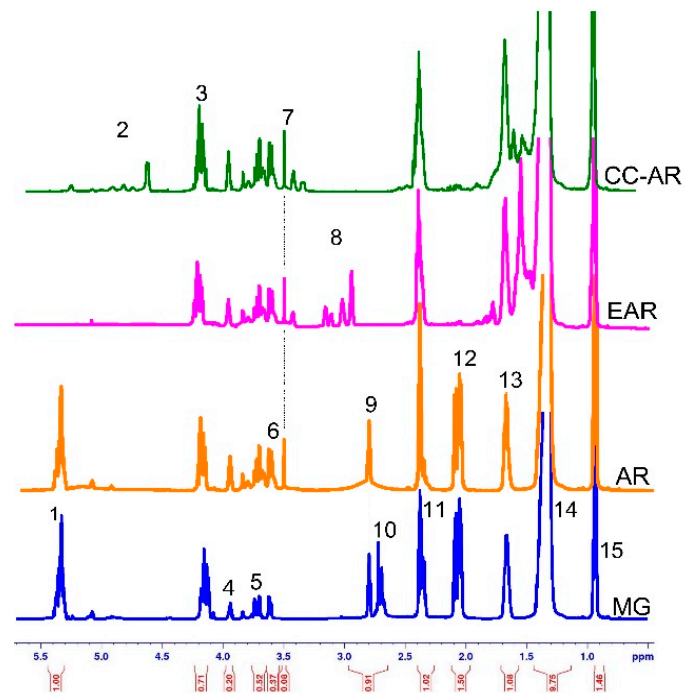

(b)

Figure 6. Spectra of catalytic carbon dioxide fixation via carbonation of epoxidized JCO based alkyd resin (a) FTIR spectra; (b) ${ }^{1} \mathrm{H}-\mathrm{NMR}$ with reaction parameters of $120^{\circ} \mathrm{C}, 2.0 \mathrm{MPa}$, and $3.5 \mathrm{~mol} \%$ of TBAB.

Figure $6 \mathrm{~b}$ shows the ${ }^{1} \mathrm{H}-\mathrm{NMR}$ spectrum of monoglyceride, wherein the corresponding chemical shift of the protons was observed between 5.5-5.32 $(1,-\mathrm{CH}=\mathrm{CH}-, 2 \mathrm{H}), 4.20-4.13\left(3, \mathrm{CH}_{2}-\mathrm{O}-\mathrm{C}=\mathrm{O}\right.$, $2 \mathrm{H}$, sn-3 glycerol protons), 3.98-3.92 (4, $\left.\mathrm{CH}_{2} \mathrm{O}-\mathrm{CO}-\mathrm{CH}_{2}-, 2 \mathrm{H}\right), 3.83-3.80(5,-\mathrm{CHOH}-, 1 \mathrm{H}), 3.64-3.59$ $\left(6,-\mathrm{CH}_{2} \mathrm{OH}-, 4 \mathrm{H}\right), 2.81-2.77\left(9,-\mathrm{CH}=\mathrm{CH}-\mathrm{CH}_{2}-\mathrm{CH}=\mathrm{CH}-, 2 \mathrm{H}\right.$, bisallylic group of $\left.\mathrm{C} 18: 2\right), 2.72-2.67$ (10, $-\mathrm{CH}_{2} \mathrm{OH}-$ and $\left.-\mathrm{CHOH}-, 2 \mathrm{H}\right), 2.4-2.3\left(\mathbf{1 1},-\mathrm{CH}_{2}-\mathrm{C}=\mathrm{O}, 6 \mathrm{H}\right), 2.1-2.0\left(\mathbf{1 2},-\mathrm{C}_{2}-\mathrm{CH}=\mathrm{CH}-, 12 \mathrm{H}\right.$, allylic $-\mathrm{CH}_{2}$ group of $\mathrm{C} 18: 2$ and $\left.\mathrm{C} 18: 1\right), 1.69-1.58\left(\mathbf{1 3}, \beta-\mathrm{CH}_{2}-, 6 \mathrm{H}\right), 1.41-1.24\left(14,-\mathrm{CH}_{2}-\right.$ of fatty acid), and $0.93-0.88\left(\mathbf{1 5}\right.$, attributed to the terminal $\mathrm{CH}_{3}$ of the fatty acid, $9 \mathrm{H}, s n-3$ is stereospecific acyl carbons [23]). Figure $6 \mathrm{~b}$ also shows the chemical shift of the AR protons, wherein the peaks were observed between 5.5-5.32 $(1,-\mathrm{C} \underline{\mathrm{H}}=\mathrm{C} \underline{\mathrm{H}}-, 2 \mathrm{H}), 4.34-4.13\left(3, \underline{\mathrm{C}}_{2}-\mathrm{O}-\mathrm{C}=\mathrm{O}, 2 \mathrm{H}\right.$, sn-3 glycerol 
protons), 3.98-3.92 (4, $\left.\mathrm{CH}_{2} \mathrm{O}-\mathrm{CO}-\mathrm{CH}_{2}-, 2 \mathrm{H}\right), 3.83-3.80(5,-\mathrm{CHOH}-, 1 \mathrm{H}), 3.64-3.59\left(6,-\mathrm{CH}_{2} \mathrm{OH}-\right.$, $4 \mathrm{H}), 3.48\left(7,-\mathrm{CH}_{2} \mathrm{OH}-, 1 \mathrm{H}\right), 2.81-2.77\left(9,-\mathrm{CH}=\mathrm{CH}-\mathrm{CH}_{2}-\mathrm{CH}=\mathrm{CH}-, 2 \mathrm{H}\right.$, bisallylic group of $\left.\mathrm{C} 18: 2\right)$, 2.4-2.3 (11, $\left.-\mathrm{CH}_{2}-\mathrm{C}=\mathrm{O}, 6 \mathrm{H}\right), 2.1-2.0\left(\mathbf{1 2},-\mathrm{CH}_{2}-\mathrm{CH}=\mathrm{CH}-, 12 \mathrm{H}\right.$, allylic $-\mathrm{CH}_{2}$ group of $\mathrm{C} 18: 2$ and $\left.\mathrm{C} 18: 1\right)$, $1.69-1.58\left(13, \beta-\mathrm{CH}_{2}-, 6 \mathrm{H}\right), 1.41-1.24\left(\mathbf{1 4},-\mathrm{CH}_{2}\right.$-of fatty acid), and 0.93-0.88 (15, attributed to the terminal $\mathrm{CH}_{3}$ of the fatty acid, $\left.9 \mathrm{H}[23]\right)$.

The functional groups of EAR and the CC-AR were confirmed by FTIR spectroscopy, as illustrated in Figure 6a, where the corresponding peaks were observed at 846 and $826 \mathrm{~cm}^{-1}$ (attributed to epoxy ring formation), $3446 \mathrm{~cm}^{-1}$ (attributed to the hydroxyl groups of EJCO), $2855 \mathrm{~cm}^{-1}$ (-C-H asymmetric stretching vibration of $-\mathrm{CH}_{2}$ groups), $3498 \mathrm{~cm}^{-1}$ (attributed to the hydroxyl groups of $\mathrm{CJCO}), 1805 \mathrm{~cm}^{-1}$ ( $\mathrm{C}=\mathrm{O}$ attributed to the stretching vibration of carbonyl), $1738 \mathrm{~cm}^{-1}$ ( $\mathrm{C}=\mathrm{O}$ stretching vibration of alkyd resin), $1652 \mathrm{~cm}^{-1}$ (assigned to $-\mathrm{CH}=\mathrm{CH}-$ ), $1464 \mathrm{~cm}^{-1}$ (attributed to $-\mathrm{CH}_{2}$ scissoring), and $1243 \mathrm{~cm}^{-1}$ (attributed to- $\mathrm{CH}_{2}$ wagging). The ${ }^{1} \mathrm{H}-\mathrm{NMR}$ spectrum exhibits the chemical shift of the EAR and CC-AR protons (Figure 6b). The peaks were observed between 3.16-3.08 (8,-CHOC $\mathrm{CHOCH}-$, diepoxides of linoleic acid), 3.02-2.96 (8, $-\mathrm{CHOCH}-\mathrm{CH}_{2}-\mathrm{CHOC} \underline{\mathrm{H}}-$, diepoxides of linoleic acid), and 2.4-2.3 (11, $\left.-\mathrm{CH}_{2}-\mathrm{C}=\mathrm{O}, 6 \mathrm{H}\right), 1.69-1.58\left(\mathbf{1 3}, \beta-\mathrm{CH}_{2}-, 6 \mathrm{H}\right), 1.41-1.24$ (14, $-\mathrm{CH}_{2}$-of fatty acid), and $0.93-0.88\left(\mathbf{1 5}\right.$, attributed to the terminal $\mathrm{CH}_{3}$ of the fatty acid, $\left.9 \mathrm{H}\right)$, respectively. The observed peaks of CC-AR between 5.06-4.52 (2, $-\mathrm{CHOCOOC} \underline{\mathrm{H}}-\mathrm{CH}_{2}-\mathrm{CHOCOOCH}-$, attributed to the carbonation of linoleic acid), 4.36-4.12 (3, $\underline{\mathrm{H}}_{2}-\mathrm{O}-\mathrm{C}=\mathrm{O}, 4 \mathrm{H}, \mathrm{sn}-3$ glycerol protons), and 2.4-2.3 (11, $\left.-\mathrm{C}_{2}-\mathrm{C}=\mathrm{O}, 6 \mathrm{H}\right)$ confirmed the five membered cyclic carbonate fixation of EAR, as illustrated in Figure 2.

\subsection{Characterization of $C J C O$ and $C C-A R$}

The wide use of TBAB is attributed to its faster epoxy conversion than that of heterogeneous catalysts [42]. The present study set the reaction temperature to $120{ }^{\circ} \mathrm{C}$ to synthesize CJCO and CC-AR with approximately $100 \%$ epoxy conversion at $2.0 \mathrm{MPa}$ in the presence of TBAB for NIPU preparation. The initial molecular weight of the JCO was $900 \mathrm{~g} \cdot \mathrm{mol}^{-1}$ which is greater than the normal vegetable oil (triglyceride, $800 \mathrm{~g} \cdot \mathrm{mol}^{-1}$ ). After chemical modification of JCO to CJCO, the molecular weight of $\mathrm{JCO}$ increased from $900 \mathrm{~g} \cdot \mathrm{mol}^{-1}$ to $1684 \mathrm{~g} \cdot \mathrm{mol}^{-1}$. This is because the higher number of unsaturated double bonds in JCO has been transferred to the cyclic carbonate functional groups in the triglyceride molecules of CJCO [8]. CC-AR demonstrated high viscosity of $3400 \pm 520 \mathrm{MPa} \cdot \mathrm{s}$, which was higher than that of $\mathrm{CJCO}$ at $25^{\circ} \mathrm{C}(2900 \pm 430 \mathrm{MPa} \cdot \mathrm{s})$ after the removal of TBAB. The number of linear fatty acid chains of the alkyd resulted in the low amount of carbonate in CJCO and CC-AR, as shown in Table 3.

Table 3. The number of linear fatty acid chains of the alkyd resulted in the low amount of carbonate in CJCO and CC-AR.

\begin{tabular}{|c|c|c|c|c|}
\hline Carbonate of JCO & ${ }^{\mathrm{a}} M\left(\mathrm{~g} \cdot \mathrm{mol}^{-1}\right)$ & b Viscosity $25^{\circ} \mathrm{C} / \mathrm{mPa} \cdot \mathrm{s}$ & Conversion $\%$ & ${ }^{\mathrm{c}}$ Carbonate Content/wt \% \\
\hline $\mathrm{CJCO}$ & 1684 & $2900 \pm 430$ & 99 & 24.9 \\
\hline CC-AR & 798 & $3400 \pm 520$ & 97 & 20.2 \\
\hline
\end{tabular}

${ }^{a}$ From GPC; ${ }^{b}$ Measured with Rheometer TA instruments; ${ }^{\mathrm{c}}{ }^{1} \mathrm{H}-\mathrm{NMR}$-spectraoscopy.

\subsection{Thermo-Mechanical Properties of the NIPU Film}

Scheme 2 illustrates the crosslinked polymer network of NIPU with $\beta$-hydroxyurethane links. FTIR spectroscopy was used to investigate the formation of the urethane bond, as illustrated in Figure 7 . The spectrum of the NIPU film assigns the peaks at $3339 \mathrm{~cm}^{-1}$ (attributed to the $-\mathrm{N}-\mathrm{H}-$ vibration of NIPU), $1704 \mathrm{~cm}^{-1}$ (attributed to the C-O stretching vibration of urethane), $1658 \mathrm{~cm}^{-1}$ (attributed to the $\mathrm{C}-\mathrm{O}-\mathrm{C}$ stretching vibration of NIPU), and $1540 \mathrm{~cm}^{-1}$ (assigned to the $\mathrm{N}-\mathrm{H}-$ bending and $\mathrm{C}-\mathrm{N}-$ vibration of NIPU). 


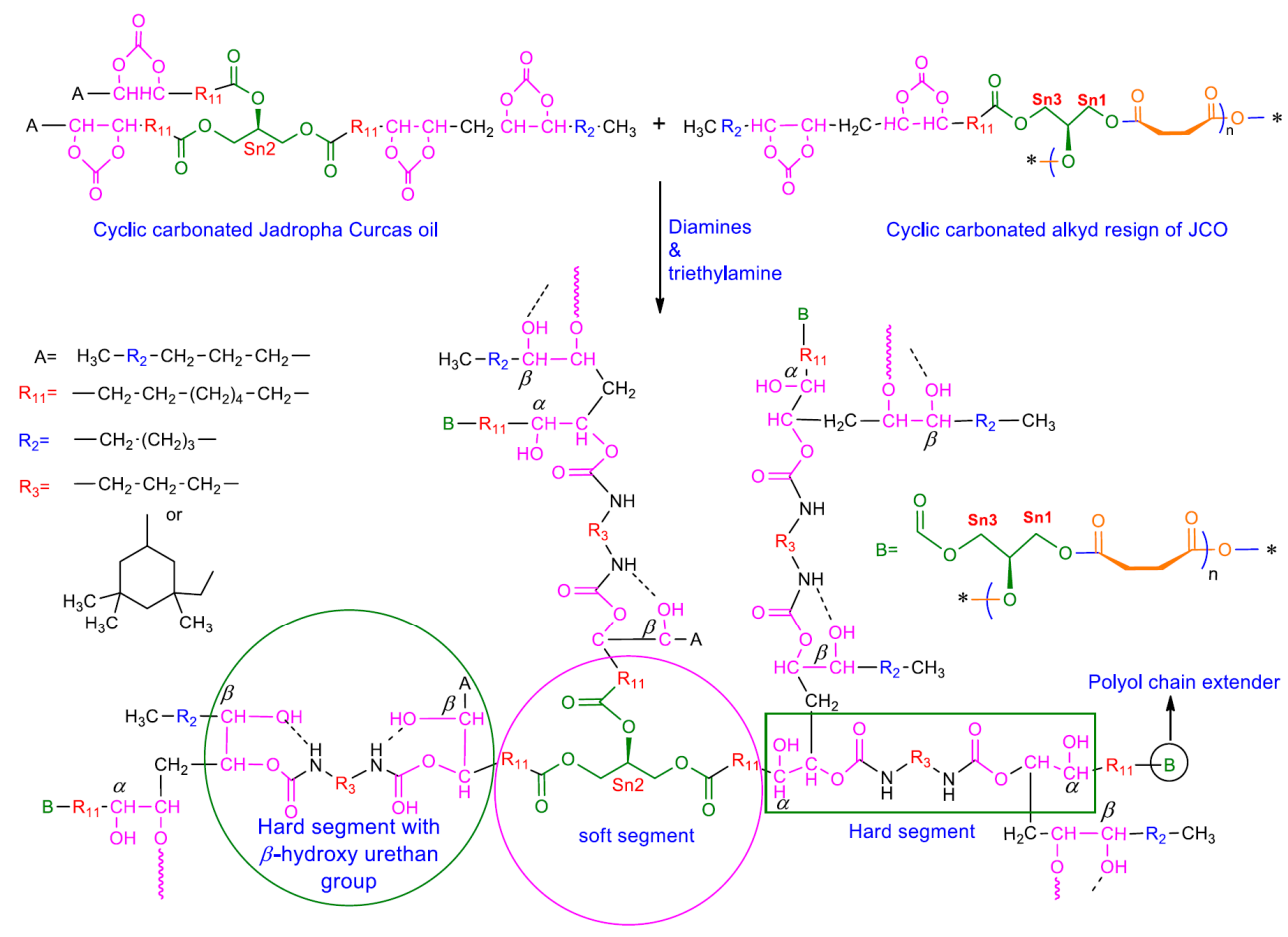

Scheme 2. The crosslinked polymer network of NIPU with $\beta$-hydroxyurethane links.

Moreover, the disappearance of the corresponding carbonyl peak at $1805 \mathrm{~cm}^{-1}$ and the hydroxyl group at 3464 and $3446 \mathrm{~cm}^{-1}$ of CJCO and CC-AR confirmed the formation of the urethane group via the complete conversion of NIPU [35]. In this study, there was no gel fraction that was found. A complete film formation occurred after a full curing reaction with diamines. This was confirmed in our FTIR study that after the curing reaction with IPDA, a complete urethane characteristic peak was observed as illustrated in Figure 7.

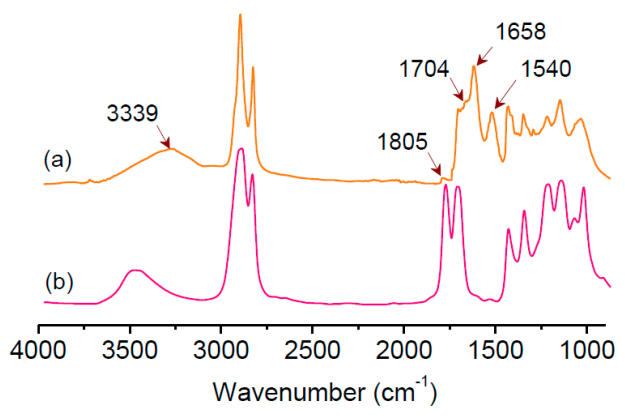

Figure 7. FTIR spectra of CJCO (a) after being cured with isophorone diamine (IPDA); (b) before curing with isophorone diamine.

The thermomechanical properties of the prepared CJCO and their blend-based NIPUs are listed in Table 4. These blends were cured with IPDA and DM, wherein CC-AR weight and amine content were used as functions to investigate their properties. Mechanical properties, such as Young's modulus, elongation at break, and tensile strength, were effectively changed with the CC-AR weight and amine content. The CJCO-based film cured with DM exhibited high elongation at break (230\%), but low modulus. However, the CJCO/CC-AR blend with a ratio of 1:3 showed significant improvement of Young's modulus of $680 \mathrm{MPa}$ with the curing agent of IPDA. This finding can be attributed to steric hindrance of the cycloaliphatic content of IPDA [46]. This finding might also be due to the structural rigidity of NIPU resulting from the highly crosslinked network structure [47]. The CJCO/CC-AR 
blend (ratio of 1:3) exhibits approximately a three times higher Young's modulus (680 MPa) and higher $T_{\mathrm{g}}$ value $\left(44^{\circ} \mathrm{C}\right)$ with IPDA compared with DM, as shown in Table 4 . The CJCO and CJCO/CC-AR blend crosslinked with IPDA show higher $T_{\mathrm{g}}$ compared to those which were crosslinked with DM due to the presence of the cycloaliphetic content in the IPDA material. In this study, the trend of $T_{\mathrm{g}}$ of the CJCO/CC-AR blends crosslinked with DM was not significant. This insignificant trend of $T_{\mathrm{g}}$ might be due to slippage between the chains of the saturated polymer matrix and the excess amount of CC-AR. The blends of CJCO/CC-AR crosslinked with IPDA show a significant drop of $T_{\mathrm{g}}$ with the increase of CC-AR composition due to the amorphous nature of CC-AR [47].

This finding can be attributed to the uniform and stoichiometric distribution of the high and low five-member cyclic carbonate functionalities of CJCO and CC-AR, which enhanced the crosslink density of the polymerization network [44]. However, the blend of CJCO/CC-AR with high CC-AR composition (ratio of 1:4) shows a reduction in modulus and tensile strength properties compared with the NIPU-based blend with CC-AR in the ratio of $1: 3(w / w)$. It is believed that the saturation and uniform distribution has been achieved in the CJCO/CC-AR blend with the blend ratio of 1:3. Thus, the further increase of CC-AR in the CJCO/CC-AR blend with the ratio of 1:4 (w/w) would result in slipping between the chains of the saturated polymer matrix [48]. Thus, the excess amount of CC-AR would jeopardize the mechanical properties of the resulting NIPU.

Table 4. Composition and thermo-mechanical properties of the fabricated NIPUs.

\begin{tabular}{|c|c|c|c|c|c|c|c|c|c|}
\hline Amine & Carbonate & $w / w$ & $\mathrm{CC} / \mathrm{wt} \%$ & Amine/wt \% & MR of A:C & $T_{\mathrm{g}} /\left({ }^{\circ} \mathrm{C}\right)$ & $\begin{array}{l}\text { E-modules } \\
\text { (MPa) }\end{array}$ & TS (MPa) & Break (\%) \\
\hline $\mathrm{DM}$ & $\mathrm{CJCO}$ & 1 & 24.9 & 17.8 & $6: 1$ & 23 & $4 \pm 2$ & $5 \pm 1$ & $230 \pm 40$ \\
\hline IPDA & $\mathrm{CJCO}$ & 1 & 24.9 & 34.3 & $9: 1$ & 54 & $150 \pm 30$ & $17 \pm 2$ & $67 \pm 28$ \\
\hline \multirow[t]{4}{*}{$\mathrm{DM}$} & $\mathrm{CJCO} / \mathrm{CC}-\mathrm{AR}$ & $1: 1$ & 22.6 & 14.7 & $5: 2$ & 22 & $12 \pm 3$ & $11 \pm 2$ & $210 \pm 20$ \\
\hline & CJCO/CC-AR & $1: 2$ & 21.8 & 20.5 & $3: 1$ & 25 & $70 \pm 10$ & $8 \pm 1$ & $130 \pm 10$ \\
\hline & CJCO/CC-AR & $1: 3$ & 21.4 & 27.3 & $3: 1$ & 21 & $220 \pm 40$ & $10 \pm 2$ & $80 \pm 30$ \\
\hline & CJCO/CC-AR & $1: 4$ & 21.1 & 22.3 & $7: 3$ & 27 & $108 \pm 10$ & $5 \pm 2$ & $54 \pm 30$ \\
\hline \multirow[t]{4}{*}{ IPDA } & CJCO/CC-AR & $1: 1$ & 22.6 & 35.6 & $4: 1$ & 48 & $27 \pm 5$ & $4 \pm 0$ & $170 \pm 10$ \\
\hline & CJCO/CC-AR & $1: 2$ & 21.8 & 30.4 & $3: 1$ & 45 & $390 \pm 20$ & $6 \pm 0$ & $70 \pm 10$ \\
\hline & $\mathrm{CJCO} / \mathrm{CC}-\mathrm{AR}$ & $1: 3$ & 21.4 & 30.8 & $4: 1$ & 44 & $680 \pm 140$ & $7 \pm 2$ & $30 \pm 20$ \\
\hline & CJCO/CC-AR & $1: 4$ & 21.1 & 24.8 & $7: 3$ & 42 & $259 \pm 30$ & $4 \pm 2$ & $160 \pm 20$ \\
\hline
\end{tabular}

$\mathrm{DM}=1,3$ diaminopropane; IPDA = isophorone diamine; $\mathrm{CC}=$ carbonate content; $\mathrm{TS}=$ tensile strength; $\mathrm{MR}=$ mole ratio; $\mathrm{A}=$ amine; $\mathrm{C}=$ carbonate.

\subsection{The Solvent Effect on the Surface Interfacial Phenomena}

The solvent and chemical resistant properties of the NIPU films were measured by the swelling test. The effect of different solvents on the interfacial surface of the NIPU film was investigated based on the attractive forces caused by the polarity of the film surface and the solvent systems [36]. On one hand, the residual attractive forces are generated by the surface active functional groups, such as urethane, $\beta$-hydroxyl, ester, and alkyl groups of the hard, soft, and polyol chain extender segments of the NIPU film surface [49]. Consequently, these forces can establish a tendency to attract and retain the active species of the solvent systems when they are in contact with the film surface [50]. On the other hand, these active species, such as molecules, solvated cation, or anions, of the different solvent systems have attracted the surface active functional groups of the solid surface via sorption processes [34,35]. These sorption processes could be either negative or positive, where the negative sorption process decreases the rate of swelling while weight augmentation could result in a positive sorption process. However, the effect of different solvents on the interfacial surface of the NIPU film can be enhanced only by chemisorption and/or physisorption processes [35-37].

\subsubsection{Solvent Resistance and Surface Interfacial Phenomena of NIPU}

Figure 8 illustrates the solvent resistance of the NIPU film via interfacial phenomena. The weight percentage of the NIPU film was varied with respect to the amine content and steric hindrance of the 
alkyl groups of the NIPU film [46]. Figure 8a shows the swelling-time diagram of CJCO and its blend with CC-AR-based NIPU in water.
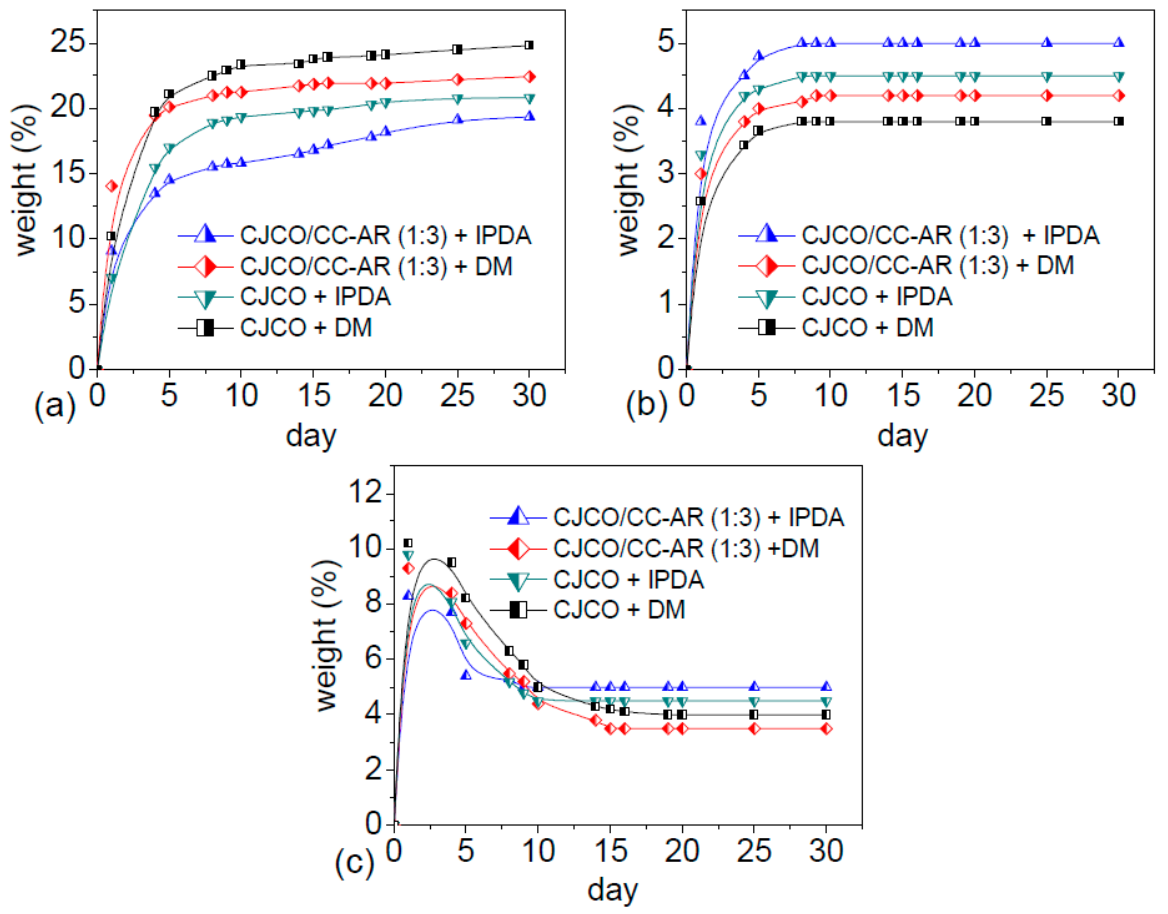

Figure 8. Swelling-time diagrams of CJCO and CJCO/CC-AR blends in (a) water; (b) solvent 30\% ethanol; (c) solvent methyl ethyl ketone.

Water adsorption on the NIPU film surface was initiated, followed by chemisorption and physisorption via cohesive interaction (intermolecular forces) of the water molecules [49,51]. These sorption processes could be enhanced by the polarity of the functional moieties of the film surface, particularly the $\beta$-hydroxyurethane groups of the hard segments. Consequently, the imbalanced residual attractive force of the NIPU film surface initiated the chemisorption process. Moreover, the interfacial surface of the NIPU film produced the monolayer via polar forces and acid-base interactions [37]. However, a lower rate of adsorption was observed in the CJCO/CC-AR blend (ratio of 1:3) with IPDA compared with the CJCO/CC-AR blend (ratio of 1:3) with DM (Figure 8a).

This phenomenon might occur due to the high steric hindrance of the cycloaliphatic content of the IPDA. The swelling behavior of the NIPU films was significantly reduced in the ethanol-water system (Figure 8b) compared with that in water (Figure 8a). This finding may be due to the strong dipole-dipole interactions of ethanol with hydronium ions in the ethanol-water system [51], which can lead to the increase of strong cohesive attraction. Ethanol is an electro-active species [52]. When ethanol is added into water, ethanol molecules like to stay in the solution due to strong interactions between the ethanol and water which reduces the rate of swelling [53].

However, the adhesive attractions of the polar ethanol molecules might be enhanced by the $\beta$-hydroxyurethane groups of the NIPU film surface via weak van der Waals forces [27] toward the film surface in the ethanol-water system. Consequently, Figure $8 \mathrm{~b}$ shows that the CJCO/CC-AR blend (ratio of 1:3) with IPDA exhibited a higher swelling rate than the CJCO/CC-AR blend (ratio of 1:3) with DM. By contrast, a slight weight loss was observed in the swelling-time diagram of the NIPU film under the MEK solvent, as shown in Figure 8c. This phenomenon could be due to the nucleophilic attraction of the ester groups on the interfacial surface [40] of the NIPU film, as illustrated in Figure 9a. This attraction might be due to steric hindrance of the alkyl groups on the film surface, which generated a strong electrostatic interaction toward the MEK molecules. 
Consequently, the chemisorption process between the MEK molecules and interfacial surface of the NIPU film resulted in polyol chain extender segments.

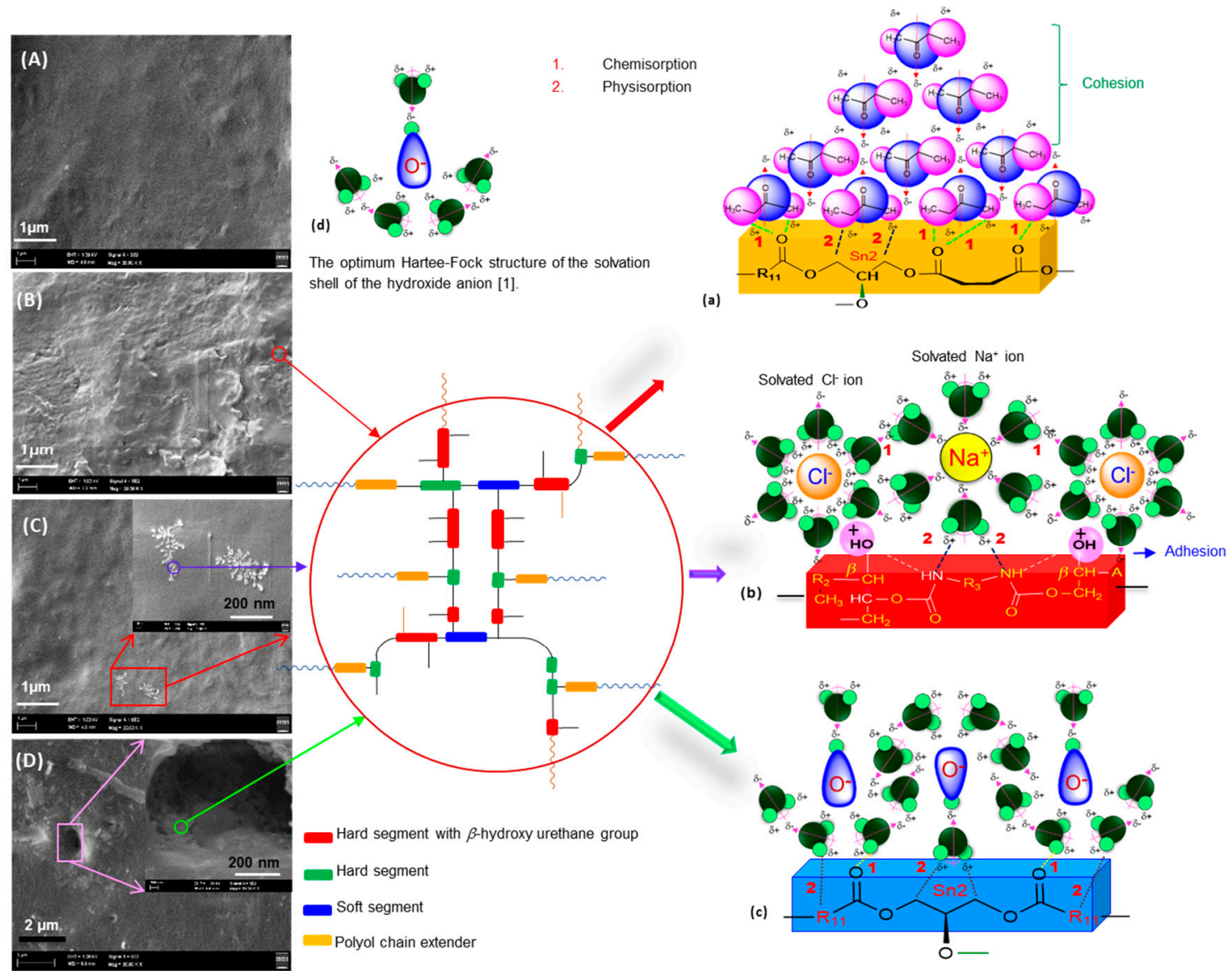

Figure 9. FESEM images of the CJCO/CC-AR blend (ratio 1:3) based NIPU with IPDA: (A) before solvent treatment; (B), (C), and (D) after solvent treatment. Interfacial surface of the NIPU: (a) after being treated with MEK; (b) after being treated with $10 \% \mathrm{NaCl}$; (c) after being treated with $5 \% \mathrm{NaOH}$; (d) the optimum Hartee-Fock structure of the solvation shell of the hydroxide anion [1].

Moreover, the polarized MEK altered the morphology of the film, as shown in Figure 9B compared with Figure 9A. This alteration may be due to the heterolytic cleavage of the polymeric chains on the interfacial surface of the NIPU film. The strong intermolecular interactions between polymer chains were established by low steric hindrance [41,42]. Furthermore, the steric hindrance of the alkyl groups on the film surface might be reduced via electrophilic attractions on the inner surface of the $\beta$-hydroxyurethane groups of the NIPU films. Consequently, the swelling behavior remains constant and differs from one another with respect to the amine content of the NIPU films.

\subsubsection{Chemical Resistance and Surface Interfacial Phenomena of NIPU}

The chemical resistance property of the NIPU films was investigated in different chemical environments, such as diluted $\mathrm{HCl}(10 \%)$, aqueous $\mathrm{NaCl}(10 \%)$, and $\mathrm{NaOH}(5 \%)$. The carbonate content, crosslinking density, $\beta$-hydroxyl moiety, and intermolecular rigidity of the blends show a significant effect on the chemical resistance behavior of the cured films. Moreover, the soft segments contribute to alteration of the film surface by chemisorption, whereas the hard segments enhance physisorption via $\beta$-hydroxyurethane hydrogen bonds. Figure 10a illustrates the swelling property of the NIPU films in diluted $\mathrm{HCl}$ solution where the CJCO-based films with DM and IPDA exhibited a slight weight loss. The strong nucleophilic attraction of the ester groups of the polyol chain extender 
segments toward the hydronium ions of the solvent could patronize this phenomenon $[54,55]$ as shown in Figure 9b. However, the cohesive attraction between the solvated chloride ions (SCI) and the hydronium ions ensures that the weight of the film remains constant [51].

By contrast, all NIPU films exhibited a significant weight augmentation in their swelling-time diagram under the $\mathrm{NaCl}$ solvent system, as shown in Figure 10b. Figure $9 \mathrm{C}$ shows the morphology of the film of the CJCO/CC-AR blend (ratio of 1:3) cured with IPDA after salt treatment. The weight augmentation might be due to the strong electrostatic interactions of the SCI toward the $\beta$-hydroxyurethane groups on the film surface, which could promote chemisorption [56].
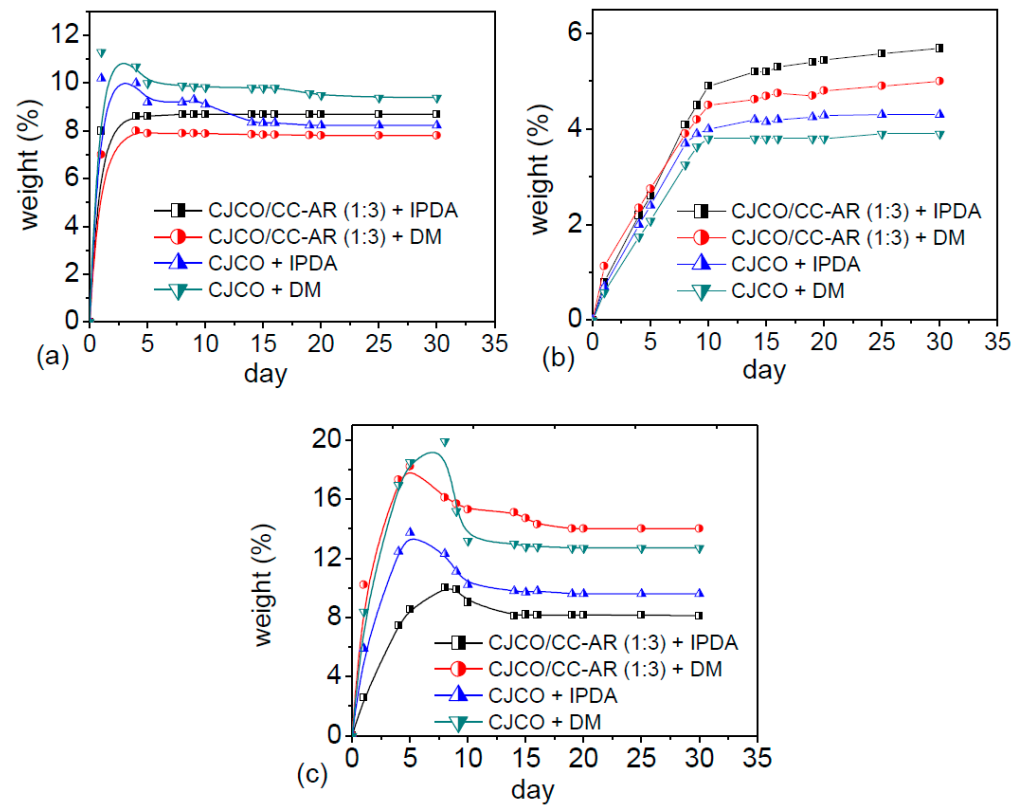

Figure 10. Swelling-time diagrams of CJCO and CJCO/CC-AR blends in (a) dilute $10 \% \mathrm{HCl}$ solution; (b) $10 \% \mathrm{NaCl}$ solution; (c) $5 \% \mathrm{NaOH}$ solution.

The weight augmentation might also be due to the electrophilic attraction of the solvated $\mathrm{Na}^{+}$ ions toward SCI [27]. The optimum Hartree-Fock structure of the solvation shell of the hydroxide anion in the $\mathrm{OH}-\left(\mathrm{H}_{2} \mathrm{O}\right)_{17}$ cluster presents four water molecules coordinated to the ${ }^{-} \mathrm{OH}$ oxygen and one water molecule coordinated to hydrogen, thus making the total solvation number of ${ }^{-} \mathrm{OH}$ in this cluster equal to 5 [57,58], as shown in Figure 9d. Consequently, Figure 10c illustrates the significant effect of the polarized solvation shell of the hydroxide anions on the swelling property of the NIPU films. This phenomenon reflects the strong chemisorption and physisorption via electrophilic attractions of the anions toward the ester groups and alkyl chains of the soft segments, as illustrated in Figure 9c. Consequently, the CJCO/CC-AR blend (ratio of 1:3) with IPDA exhibited a slight weight loss compared with the CJCO/CC-AR blend (ratio of 1:3) with DM. This phenomenon reflects the strong chemisorption and physisorption via electrophilic attractions of the anions toward the ester groups and alkyl chains of the soft segments, as illustrated in Figure 9c. Figure 9D shows that the polarized solvation shell of the hydroxide anions takes part in heterolytic cleavage of the NIPU film surface [59].

\section{Conclusions}

In this study, the carbonation of EJCO and monoglyceride-based carbonated alkyd resin was conducted successfully. The conditions for epoxidation and carbonation reactions will significantly influence the carbonate content of CJCO and CC-AR. The optimal reaction condition was set at $120^{\circ} \mathrm{C}$ and 2.0 MPa of $\mathrm{CO}_{2}$ pressure. The carbonate conversion of CJCO and CC-AR was observed at $99 \%$ 
and $97 \%$, respectively, within a $30 \mathrm{~h}$ reaction period. The carbonate content of CJCO was higher than that of CC-AR. Compared with the CJCO-based NIPU, the blend of CJCO and CC-AR-based NIPU exhibits excellent thermal, mechanical, solvent, and chemical resistance properties when cured with DM and IPDA. Furthermore, the amine and cycloaliphatic contents of IPDA play a major role in surface interfacial phenomena via sorption processes. In the present study, the strong solvent and chemical resistance properties exhibited by cured blends in different solvent environments can be ascribed to the inclusion of CC-AR in the blend. The amine content, intermolecular attractions of the polymer chains, $\beta$-hydroxyurethane hydrogen bonds, and cycloaliphatic content of IPDA can contribute to the enhancement of the interfacial surface of the CJCO/CC-AR blend. The NIPU film with high amine content (30.8\% of IPDA) exhibited better solvent and chemical resistance compared with the CJCO/CC-AR blend (ratio of 1:3) and the CJCO film cured with DM.

Acknowledgments: The authors would like to acknowledge the financial support from the Ministry of Education Malaysia: High Impact Research MoE Grant UM.C/625/1/HIR/MoE/52, FP030-2013A, and FP053-2015A; and University Malaya research grant: RU019-2015, RG031-15AET, PG159-2016A, and RU018H-2016 for the success of this project.

Author Contributions: Mhd. Abd. Cader M. Haniffa wrote the paper; Mhd. Abd. Cader M. Haniffa and Yern Chee Ching initiated and contributed to the scope of the manuscript; Yern Chee Ching, Cheng Hock Chuah, Yong Ching Kuan and De-Shin Liu planned the structure and revised the manuscript, De-Shin Liu, Yern Chee Ching, Cheng Hock Chuah, Yong Ching Kuan and Nai-Shang Liou critically reviewed the manuscript.

Conflicts of Interest: The authors declare no conflict of interest.

\section{References}

1. Gogoi, P.; Boruah, M.; Sharma, S.; Dolui, S.K. Blends of epoxidized alkyd resins based on jatropha oil and the epoxidized oil cured with aqueous citric acid solution: A green technology approach. ACS Sustain. Chem. Eng. 2015, 3, 261-268. [CrossRef]

2. Lim, K.M.; Ching, Y.C.; Gan, S.N. Effect of palm oil bio-based plasticizer on the morphological, thermal and mechanical properties of poly(vinyl chloride). Polymers 2015, 7, 2031-2043. [CrossRef]

3. de Espinosa, L.M.; Meier, M.A. Plant oils: The perfect renewable resource for polymer science? Eur. Polym. J. 2011, 47, 837-852. [CrossRef]

4. Biermann, U.; Bornscheuer, U.; Meier, M.A.; Metzger, J.O.; Schäfer, H.J. Oils and fats as renewable raw materials in chemistry. Angew. Chem. Int. Ed. 2011, 50, 3854-3871. [CrossRef] [PubMed]

5. Zhang, L.; Luo, Y.; Hou, Z.; He, Z.; Eli, W. Synthesis of carbonated cotton seed oil and its application as lubricating base oil. J. Am. Oil Chem. Soc. 2014, 91, 143-150. [CrossRef]

6. Mhd Haniffa, M.A.C.; Ching, Y.C.; Abdullah, L.C.; Poh, S.C.; Chuah, C.H. Review of bionanocomposite coating films and their applications. Polymers 2016, 8, 246. [CrossRef]

7. Makkar, H.P.; Becker, K. Jatropha curcas, a promising crop for the generation of biodiesel and value-added coproducts. Eur. J. Lipid Sci. Technol. 2009, 111, 773-787. [CrossRef]

8. Kumar, A.; Sharma, S. An evaluation of multipurpose oil seed crop for industrial uses Jatropha curcas L: A review. Ind. Crops Prod. 2008, 28, 1-10. [CrossRef]

9. Segura-Campos, M.R.; Betancur-Ancona, D. The Promising Future of Jatropha curcas: Properties and Potential Applications; Nova Science Publishers Incorporated: Hauppauge, NY, USA, 2016.

10. Abdulla, R.; Chan, E.S.; Ravindra, P. Biodiesel production from Jatropha curcas: A critical review. Crit. Rev. Biotechnol. 2011, 31, 53-64. [CrossRef] [PubMed]

11. Chen, C.R.; Cheng, Y.-J.; Ching, Y.C.; Chang, C.M.; Hsiang, D. Green production of energetic jatropha oil from de-shelled Jatropha curcas L. seeds using carbon dioxide extraction. J. Supercrit. Fluids 2012, 66, 137-143. [CrossRef]

12. Hazmi, A.S.A.; Aung, M.M.; Abdullah, L.C.; Salleh, M.Z.; Mahmood, M.H. Producing jatropha oil-based polyol via epoxidation and ring opening. Ind. Crops Prod. 2013, 50, 563-567. [CrossRef]

13. Lestari, D.; Mulder, W.J.; Sanders, J.P. Jatropha seed protein functional properties for technical applications. Biochem. Eng J. 2011, 53, 297-304. [CrossRef]

14. Aung, M.M.; Yaakob, Z.; Kamarudin, S.; Abdullah, L.C. Synthesis and characterization of jatropha Jatropha curcas L. oil-based polyurethane wood adhesive. Ind. Crops Prod. 2014, 60, 177-185. [CrossRef] 
15. Gogoi, P.; Boruah, M.; Bora, C.; Dolui, S.K. Jatropha curcas oil based alkyd/epoxy resin/expanded graphite (EG) reinforced bio-composite: Evaluation of the thermal, mechanical and flame retardancy properties. Prog. Org. Coat. 2014, 77, 87-93. [CrossRef]

16. Gofferje, G.; Schmid, M.; Stäbler, A. Characterization of Jatropha curcas L. Protein cast films with respect to packaging relevant properties. Int. J. Polym. Sci. 2015, 2015. [CrossRef]

17. Boruah, M.; Gogoi, P.; Adhikari, B.; Dolui, S.K. Preparation and characterization of Jatropha curcas oil based alkyd resin suitable for surface coating. Prog. Org. Coat. 2012, 74, 596-602. [CrossRef]

18. Liao, L.; Li, X.; Wang, Y.; Fu, H.; Li, Y. Effects of surface structure and morphology of nanoclays on the properties of Jatropha curcas oil-based waterborne polyurethane/clay nanocomposites. Ind. Eng. Chem. Res. 2016, 55, 11689-11699. [CrossRef]

19. Hong, L.K.; Yusop, R.M.; Salih, N.; Salimon, J. Pengoptimuman tindakbalas pengepoksidaan in situ asid linoleik minyak Jatropha curcas dengan asid performik. Malays. J. Anal. Sci. 2015, 19, 144-154.

20. Kamil, R.N.M.; Yusup, S.; Rashid, U. Optimization of polyol ester production by transesterification of jatropha-based methyl ester with trimethylolpropane using taguchi design of experiment. Fuel 2011, 90, 2343-2345. [CrossRef]

21. Tapanes, N.C.O.; Aranda, D.A.G.; de Mesquita Carneiro, J.W.; Antunes, O.A.C. Transesterification of Jatropha curcas oil glycerides: Theoretical and experimental studies of biodiesel reaction. Fuel 2008, 87, 2286-2295. [CrossRef]

22. Rosillo-Calle, F.; Pelkmans, L.; Walter, A. A global overview of vegetable oils, with reference to biodiesel. Rep. Bioenergy Task 2009, 40.

23. López Téllez, G.; Vigueras-Santiago, E.; Hernández-López, S. Characterization of linseed oil epoxidized at different percentages. Superf. Y Vacío 2009, 22, 5-10.

24. Da Silva, N.D.L.; Batistella Filho, C. Determination of castor oil molecular weight by vapour pressure osmometry technique. Chem. Eng. Trans. 2011, 24, 601-606.

25. Doll, K.M.; Erhan, S.Z. The improved synthesis of carbonated soybean oil using supercritical carbon dioxide at a reduced reaction time. Green Chem. 2005, 7, 849-854. [CrossRef]

26. Li, Z.; Zhao, Y.; Yan, S.; Wang, X.; Kang, M.; Wang, J.; Xiang, H. Catalytic synthesis of carbonated soybean oil. Catal. Lett. 2008, 123, 246-251. [CrossRef]

27. Supasitmongkol, S.; Styring, P. A single centre aluminium (III) catalyst and tbab as an ionic organo-catalyst for the homogeneous catalytic synthesis of styrene carbonate. Catal. Sci. Technol. 2014, 4, 1622-1630. [CrossRef]

28. Tamami, B.; Sohn, S.; Wilkes, G. Incorporation of carbon dioxide into soybean oil and subsequent preparation and studies of nonisocyanate polyurethane networks. J. Appl. Polym. Sci. 2004, 92, 883-891. [CrossRef]

29. Javni, I.; Hong, D.P.; Petrović, Z.S. Soy-based polyurethanes by nonisocyanate route. J. Appl. Polym. Sci. 2008, 108, 3867-3875. [CrossRef]

30. Mazo, P.C.; Rios, L.A. Improved synthesis of carbonated vegetable oils using microwaves. Chem. Eng. J. 2012, 210, 333-338. [CrossRef]

31. Parzuchowski, P.G.; Jurczyk-Kowalska, M.; Ryszkowska, J.; Rokicki, G. Epoxy resin modified with soybean oil containing cyclic carbonate groups. J. Appl. Polym. Sci. 2006, 102, 2904-2914. [CrossRef]

32. Comerford, J.W.; Ingram, I.D.; North, M.; Wu, X. Sustainable metal-based catalysts for the synthesis of cyclic carbonates containing five-membered rings. Green Chem. 2015, 17, 1966-1987. [CrossRef]

33. Chevereau, E.; Zouaoui, N.; Limousy, L.; Dutournié, P.; Déon, S.; Bourseau, P. Surface properties of ceramic ultrafiltration tio 2 membranes: Effects of surface equilibriums on salt retention. Desalination 2010, 255, 1-8. [CrossRef]

34. Cacace, M.; Landau, E.; Ramsden, J. The hofmeister series: Salt and solvent effects on interfacial phenomena. Q. Rev. Biophys. 1997, 30, 241-277. [CrossRef] [PubMed]

35. Ching, Y.C.; Iskandar, I.Y. Influence of nano- $\mathrm{SiO}_{2} /$ polyamide composites coating on thermic effect and optical properties of polyethylene film. Int. J. Mod. Phys. B 2009, 23, 1395-1400.

36. Khoon, S.C.; Ching, Y.C.; Ng, C.A.; Ishenny, N.; Beg, M.T. Effect of polyurethane/nanosilica composite coating on water resistance of paper substrate. Mater. Res. Innov. 2014, 18, 368-371.

37. Schumacher, R. The quartz microbalance: A novel approach to the in-situ investigation of interfacial phenomena at the solid/liquid junction (new analytical methods (40)). Angew. Chem. Int. Ed. 1990, 29, 329-343. [CrossRef]

38. He, Z.; Wang, Y.; Zhao, T.; Ye, Z.; Huang, H. Ultrasonication-assisted rapid determination of epoxide values in polymer mixtures containing epoxy resin. Anal. Methods 2014, 6, 4257-4261. [CrossRef] 
39. Cornille, A.; Michaud, G.; Simon, F.; Fouquay, S.; Auvergne, R.; Boutevin, B.; Caillol, S. Promising mechanical and adhesive properties of isocyanate-free poly(hydroxyurethane). Eur. Polym. J. 2016, 84, 404-420. [CrossRef]

40. Bergman, T.L.; Incropera, F.P.; DeWitt, D.P.; Lavine, A.S. Fundamentals of Heat and Mass Transfer; John Wiley \& Sons: Hoboken, NJ, USA, 2011.

41. Zheng, J.L.; Burel, F.; Salmi, T.; Taouk, B.; Leveneur, S.B. Carbonation of vegetable oils: Influence of mass transfer on reaction kinetics. Ind. Eng. Chem. Res. 2015, 54, 10935-10944. [CrossRef]

42. Motokura, K.; Itagaki, S.; Iwasawa, Y.; Miyaji, A.; Baba, T. Silica-supported aminopyridinium halides for catalytic transformations of epoxides to cyclic carbonates under atmospheric pressure of carbon dioxide. Green Chem. 2009, 11, 1876-1880. [CrossRef]

43. Bähr, M.; Mülhaupt, R. Linseed and soybean oil-based polyurethanes prepared via the non-isocyanate route and catalytic carbon dioxide conversion. Green Chem. 2012, 14, 483-489. [CrossRef]

44. Fleischer, M.; Blattmann, H.; Mülhaupt, R. Glycerol-, pentaerythritol- and trimethylolpropane-based polyurethanes and their cellulose carbonate composites prepared via the non-isocyanate route with catalytic carbon dioxide fixation. Green Chem. 2013, 15, 934-942. [CrossRef]

45. Figovsky, O.; Shapovalov, L.; Buslov, F. Ultraviolet and thermostable non-isocyanate polyurethane coatings. Surf. Coat. Int. B Coat. Trans. 2005, 88, 67-71. [CrossRef]

46. Babak, V.G.; Desbrieres, J.; Tikhonov, V.E. Dynamic surface tension and dilational viscoelasticity of adsorption layers of a hydrophobically modified chitosan. Colloids Surf. A 2005, 255, 119-130. [CrossRef]

47. Pathan, S.; Ahmad, S. Synthesis, characterization and the effect of the s-triazine ring on physico-mechanical and electrochemical corrosion resistance performance of waterborne castor oil alkyd. J. Mater. Chem. A 2013, 1, 14227-14238. [CrossRef]

48. Pramanik, S.; Kar, K.K. Functionalized poly(ether ether ketone): Improved mechanical property and acellular bioactivity. J. Appl. Polym. Sci. 2012, 123, 1100-1111. [CrossRef]

49. Xia, Y.; Zhao, H.; Liu, S.; Zhang, T. The humidity-sensitive property of mcm-48 self-assembly fiber prepared via electrospinning. RSC Adv. 2014, 4, 2807-2812. [CrossRef]

50. Ching, Y.C.; Chen, Y.C.; Kalam, A.; Iskandar, Y.I. Comparison use of suspended cell system and polyurethane base immobilized cell system in biological treatment of wastewater. Res. J. Chem. Environ. 2011, 15, 849-855.

51. Waite, J.H. Mussel adhesion-Essential footwork. J. Exp. Biol. 2017, 220, 517-530. [CrossRef] [PubMed]

52. Arjona, N.; Trejo, G.; Ledesma-García, J.; Arriaga, L.; Guerra-Balcázar, M. An electrokinetic-combined electrochemical study of the glucose electro-oxidation reaction: Effect of gold surface energy. RSC Adv. 2016, 6, 15630-15638. [CrossRef]

53. Ozmen, M.M.; Okay, O. Swelling behavior of strong polyelectrolyte poly(n-t-butylacrylamide-co-acrylamide) hydrogels. Eur. Polym. J. 2003, 39, 877-886. [CrossRef]

54. Ching, Y.C.; Iskander, I.Y. Effect of Polyurethane/nanosilica composites Coating on thermo-mechanical properties of polyethylene film. Mater. Technol. 2012, 27, 113-115. [CrossRef]

55. Ching, Y.C.; Nurehan, S. Effect of nanosilica filled polyurethane composite coating on polypropylene substrate. J. Nanomaterials 2013, 10, 567-578. [CrossRef]

56. Morawetz, H. Kinetics of intramolecular and intermolecular reactions involving two functional groups attached to polymers. Pure Appl. Chem. 1974, 38, 267-277. [CrossRef]

57. Novoa, J.J.; Mota, F.; Perez del Valle, C.; Planas, M. Structure of the first solvation shell of the hydroxide anion. A model study using $\mathrm{OH}^{-}\left(\mathrm{H}_{2} \mathrm{O}\right)_{\mathrm{n}}(n=4,5,6,7,11,17)$ clusters. J. Phys. Chem. A 1997, 101, 7842-7853. [CrossRef]

58. Rabuni, M.F.; Nik Sulaiman, N.; Aroua, M.K.; Ching, Y.C.; Awanis, N.H. Impact of in situ physical and chemical cleaning on PVDF membrane properties and performances. Chem. Eng. Sci. 2015, 122, 426-435. [CrossRef]

59. Nurul, A.S.; Awanis, H.; Nik Meriam, N.S.; Ching, Y.C. Alkaline etching treatment of pvdf membrane for water filtration. RSC Adv. 2016, 6, 22153-22160.

(C) 2017 by the authors. Licensee MDPI, Basel, Switzerland. This article is an open access article distributed under the terms and conditions of the Creative Commons Attribution (CC BY) license (http:/ / creativecommons.org/licenses/by/4.0/). 